\author{
By \\ Prasanth Chandrasekar \\ Bachelor of Engineering in Aeronautical Engineering \\ Anna University, Chennai- India, 2014
}

\author{
A report \\ presented to Ryerson University \\ in partial fulfillment of the \\ requirement for the degree of \\ Master of Engineering \\ in the Program of \\ Aerospace Engineering
}

Toronto, Ontario, Canada, 2016

(C) Prasanth Chandrasekar 2016 


\section{AUTHOR'S DECLARATION}

I hereby declare that I am the sole author of this thesis. This is a true copy of the thesis, including any required final revisions, as accepted by my examiners.

I authorize Ryerson University to lend this thesis to other institutions or individuals for the purpose of scholarly research.

I further authorize Ryerson University to reproduce this thesis by photocopying or by other means, in total or in part, at the request of other institutions or individuals for the purpose of scholarly research.

I understand that my thesis may be made electronically available to the public. 


\title{
THE INFLUENCE OF STRESS LEVEL ON THE RATCHETING MAGNITUDE AND PROGRESS RATE IN STEEL ALLOYS UNDER UNIAXIAL LOADING CONDITIONS
}

\author{
Master of Engineering in Aerospace Engineering \\ Ryerson University, Toronto, 2016 \\ Prasanth Chandrasekar, 2016
}

\begin{abstract}
Engineering materials in their service life undergo symmetric or asymmetric fatigue loading, which leads to fatigue damage in the material. Ratcheting damage is due to the application of mean stress under cyclic loading condition. From deformation behavior perspective, application of mean stress under stress-controlled fatigue loading gives rise to accumulation of plastic strain in the material. Ratcheting strain increases with an increase in applied mean stress and stress amplitude. In addition, ratcheting behavior will increase in cyclic damage with the rise in strain accumulation and it can be illustrated by a shift in the hysteresis loop towards large plastic strain amplitudes. This study focuses on the ratcheting behavior of different steel materials under uniaxial cyclic loading condition and suggests a suitable method to arrest ratcheting by loading the materials at zero ratcheting strain rate condition with specified mean stress and stress amplitudes. The threedimensional surface is created with stress amplitude, mean stress and ratcheting strain rate for different steel materials. This represents a graphical surface zone to study the ratcheting strain rates for various mean stress and stress amplitude combinations.
\end{abstract}

Keywords: fatigue loading, ratcheting strain, cyclic damage, mean stress and stress amplitudes, plastic strain amplitude, ratcheting strain rate, graphical surface zone. 


\section{ACKNOWLEDGEMENTS}

After thanking God, I am heartily thankful to my supervisor, Dr. Ahmad Varvani, whose help, guidance and support during my Master's program provided me with significant knowledge in fatigue analysis. I express my deepest gratitude for his advice, detailed review and constructive comments and criticism during my research. It was a great opportunity to work under his supervision.

Also, I would like to thank my parents, my friends and every person that supported me even with a word. 


\section{TABLE OF CONTENTS}

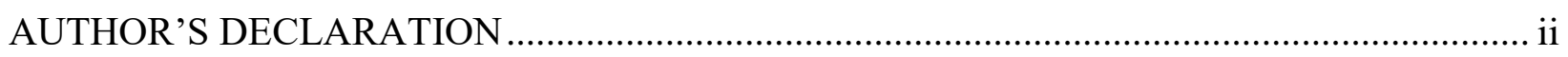

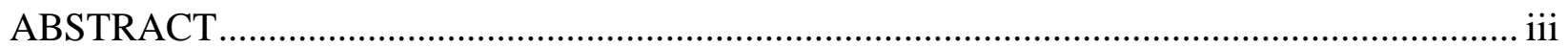

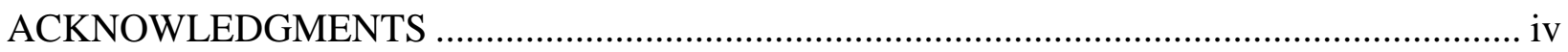

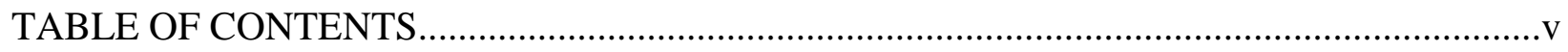

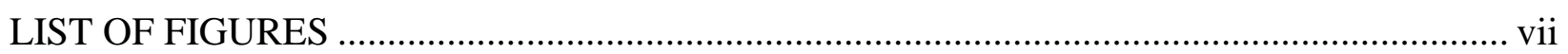

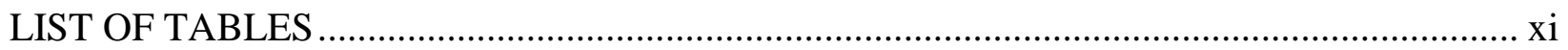

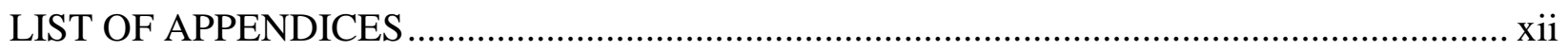

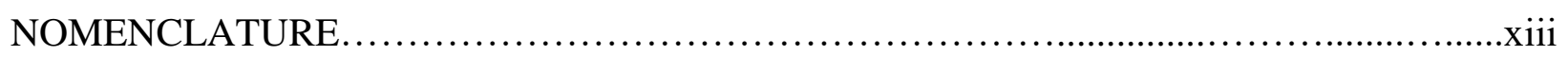

CHAPTER 1: Problem Definition and Introduction................................................

1.1 Problem Definition......................................................

1.2 Introduction..................................................................

1.3 Ratcheting Assessment..............................................................................

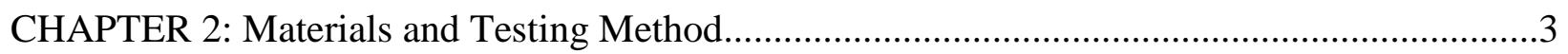

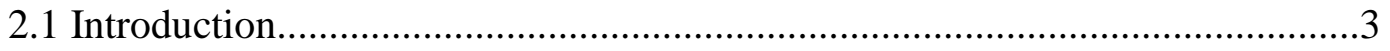

2.2 Experimental Ratcheting Test.....................................................................

2.3 Accumulation of Ratcheting Strain....................................................................5

CHAPTER 3: Mathematical Models for Ratcheting Strain Prediction............................................

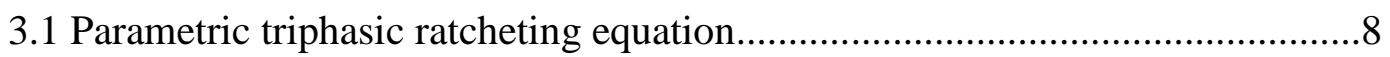

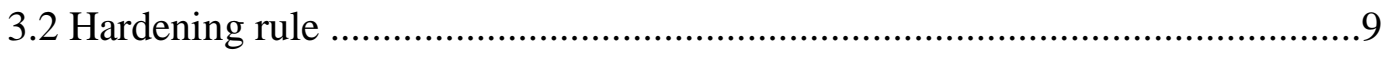

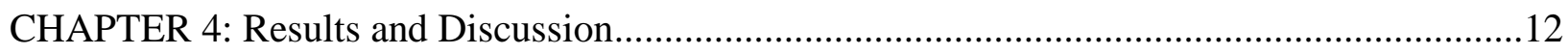

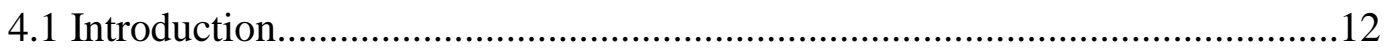


4.2 Ratcheting strain rate at stage II.

4.3 Mean and amplitude stress relations......................................................23

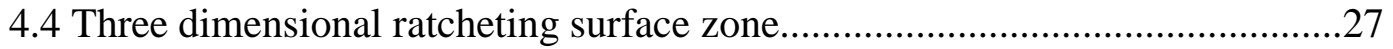

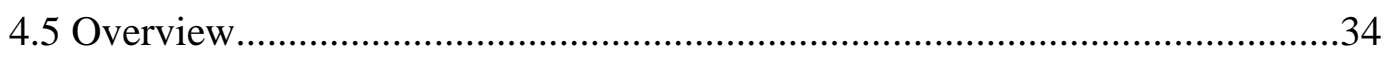

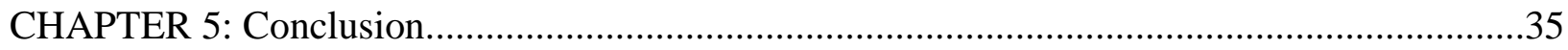

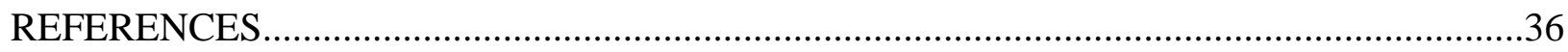




\section{LIST OF FIGURES}

Fig. 1.1 Schematic triphasic trend of ratcheting strain over a stress cycles $\quad \ldots \ldots \ldots \ldots . . . .2$

Fig. $2.1 \quad$ Specimen geometry for ratcheting test $\quad$.............. 3

Fig. 2.2 schematic loading path for ratcheting test $\quad$............. 4

Fig. 2.3 Various ratcheting strains with 100 loading cycles for different mean stress and constant stress amplitudes of (a) $130 \mathrm{MPa}$ (b) 140 $\mathrm{MPa}$ (c) $150 \mathrm{MPa}$ in IF steel

Fig. 2.4 (a) Various ratcheting strains with 100 loading cycles for different stress amplitude and constant mean stress of $10 \mathrm{MPa}$ and varying stress amplitude of 130, 140 and $150 \mathrm{MPa}$ in IF steel

Fig. 3.1 Parametric triphasic ratcheting strain over $N_{f}$

Fig. 4.1 Slope of a $/ \mathrm{b}$ represent the ratcheting stain rate for IF steel for (a) constant stress amplitude of $130 \mathrm{MPa}$ with varying mean stress (b) 12 constant mean stress of $10 \mathrm{MPa}$ with varying stress amplitude

Fig. 4.2 (a) Ratcheting strain rate vs. mean stress at constant stress amplitude of $360 \mathrm{MPa}$ (b) ratcheting strain rate vs. stress amplitude at constant 13 mean stress of $100 \mathrm{MPa}$ is plotted for $16 \mathrm{MnR}$ steel

Fig. 4.3 (a) Ratcheting strain rate vs. mean stress at constant stress amplitude of 130,140 and $150 \mathrm{MPa}$ (b) ratcheting strain rate vs. stress amplitude at constant mean stress of $10 \mathrm{MPa}$ is plotted for interstitial free steel

Fig. 4.4 (a) Ratcheting strain rate vs. mean stress at constant stress amplitude of $300 \mathrm{MPa}$ (b) ratcheting strain rate vs. stress amplitude at constant 14 mean stress of $10 \mathrm{MPa}$ is plotted for SS304

Fig. 4.5 (a) Ratcheting strain rate vs. mean stress at constant stress amplitude of $350 \mathrm{MPa}(\mathrm{b})$ ratcheting strain rate vs. stress amplitude at constant mean stress of $50 \mathrm{MPa}$ is plotted for $42 \mathrm{CrMo}$ steel 
Fig. 4.6 (a) Ratcheting strain rate vs. mean stress at constant stress amplitude of $144.2 \mathrm{MPa}$ (b) ratcheting strain rate vs. stress amplitude at constant mean stress of $28.84 \mathrm{MPa}$ is plotted for titanium-stabilized ….......... 15 steel

Fig. 4.7 (a) Ratcheting strain rate vs. mean stress at constant stress amplitude of $350 \mathrm{MPa}$ is plotted for $42 \mathrm{CrMo}$ steel (b) ratcheting strain rate vs. stress amplitude at constant mean stress of $50 \mathrm{MPa}$ is plotted for 15 1020 steel

Fig. 4.8 (a) Ratcheting strain rate vs. mean stress at constant stress amplitude of $310 \mathrm{MPa}$ is plotted for SA 333 Gr6C-Mn steel (b) ratcheting strain rate vs. stress amplitude at constant mean stress of $50 \mathrm{MPa}$ is plotted for 20CS steel

Fig. 4.9 (a) Ratcheting strain rate vs. mean stress at constant stress amplitude of $382 \mathrm{MPa}$ (b) ratcheting strain rate vs. stress amplitude at constant mean stress of $637 \mathrm{MPa}$ is plotted for X13CrMnMoN18-14-3 high 16 nitrogen steel

Fig. 4.10 (a) Ratcheting strain rate vs. mean stress at constant stress amplitude of $200 \mathrm{MPa}$ (b) ratcheting strain rate vs. stress amplitude at constant 17 mean stress of $125 \mathrm{MPa}$ is plotted for Z2CND18-12N steel

Fig. 4.11 (a) Ratcheting strain rate vs. mean stress at constant stress amplitude and (b) ratcheting strain rate vs. stress amplitude at constant mean 17 stress is plotted for three different steel

Fig. 4.12 (a) Ratcheting strain rate vs. mean stress at constant stress amplitude of $350 \mathrm{MPa}(\mathrm{b})$ ratcheting strain rate vs. stress amplitude at constant 18 mean stress of $30 \mathrm{MPa}$ is plotted for HC340LA steel

Fig. 4.13 (a) Ratcheting strain rate vs. mean stress at constant stress amplitude of $600 \mathrm{MPa}(\mathrm{b})$ ratcheting strain rate vs. stress amplitude at constant 18 mean stress of $100 \mathrm{MPa}$ is plotted for HC340LA steel

Fig. 4.14 (a) Ratcheting strain rate vs. mean stress at constant stress amplitude and (b) ratcheting strain rate vs. stress amplitude at constant mean 19 stress of is plotted for 304LN Stainless steel and 20 Steel 
Fig. 4.15 Mean and amplitude stress relation for $16 \mathrm{MnR}$ steel at yield stress of $378 \mathrm{MPa}$

Fig. 4.16 Mean and amplitude stress relation for interstitial free steel at yield stress of $200 \mathrm{MPa}$

Fig. 4.17 Mean and amplitude stress relation for SS304 steel at yield stress of $209 \mathrm{MPa}$

Fig. 4.18 Mean and amplitude stress relation for 42CrMo steel at yield stress of $310 \mathrm{MPa}$

Fig. 4.19 Mean and amplitude stress relation for titanium-stabilized interstitial free steel at yield stress of 144.2 $\mathrm{MPa}$

Fig. 4.20 Mean and amplitude stress relation for 42CrMo steel at yield stress of $310 \mathrm{MPa}$

Fig. 4.21 Mean and amplitude stress relation for X13CrMnMoN 18-14-3 high nitrogen steel at yield stress of $830 \mathrm{MPa}$

Fig. 4.22 Mean and amplitude stress relation for Z2CND18.12N steel at yield stress of $85 \mathrm{MPa}$

Fig. 4.23 Mean and amplitude stress relation for 316L steel at yield stress of $285 \mathrm{MPa}$

Fig. 4.24 Mean and amplitude stress relation for HC340LA steel at yield stress of $477 \mathrm{MPa}$

Fig. 4.25 Mean and amplitude stress relation for 304LN steel at yield stress of $353 \mathrm{MPa}$

Fig. 4.26 Mean and amplitude stress relation for 20 Steel at yield stress of 250 $\mathrm{MPa}$

Fig. 4.27 Three dimensional ratcheting surface zone for applied stress amplitude and mean stress for interstitial free steel

Fig. 4.28 Three dimensional ratcheting surface zone for applied stress amplitude and mean stress for $16 \mathrm{MnR}$ steel

Fig. 4.29 Three dimensional ratcheting surface zone for applied stress amplitude and mean stress for SS304 stainless steel 
Fig. 4.30 Three dimensional ratcheting surface zone for applied stress amplitude and mean stress for 42CrMo steel

Fig. 4.31 Three dimensional ratcheting surface zone for applied stress amplitude and mean stress for titanium-stabilized free steel

Fig. 4.32 Three dimensional ratcheting surface zone for applied stress amplitude and mean stress for X13CrMnMoN18-14-3 high nitrogen steel

Fig. 4.33 Three dimensional ratcheting surface zone for applied stress amplitude and mean stress for Z2CND18-12N steel

Fig. 4.34 Three dimensional ratcheting surface zone for applied stress amplitude and mean stress for SS316L steel

Fig. 4.35 Three dimensional ratcheting surface zone for applied stress amplitude and mean stress for HC340LA steel alloy

Fig. 4.36 Three dimensional ratcheting surface zone for applied stress amplitude and mean stress for 30LN stainless steel

Fig. 4.37 Three dimensional ratcheting surface zone for applied stress amplitude and mean stress for 20 steel 


\section{LIST OF TABLES}

Table 2.1 Mean stress and stress amplitude for ratcheting test in interstitial free (IF) steel

Table 4.1 Slope, y-intercept, mean stress and stress amplitude values at zero ratcheting strain for different steels

Table 4.2 Values of the exponential equation constants in mean and amplitude stress relation graphs for different steel 26 materials 


\section{LIST OF APPENDICES}

APPENDIX A $\quad$ Mechanical Properties of materials $\quad$...................... 38

APPENDIX B Ratcheting strain rate of materials $\quad$....................... 30

APPENDIX C MATLAB code to generate plots for ratcheting strain rate vs. mean stress

APPENDIX D MATLAB code used to generate plots for mean stress vs. amplitude stress

APPENDIX E MATLAB code used to generate three dimensional surface 


\section{NOMENCLATURES}

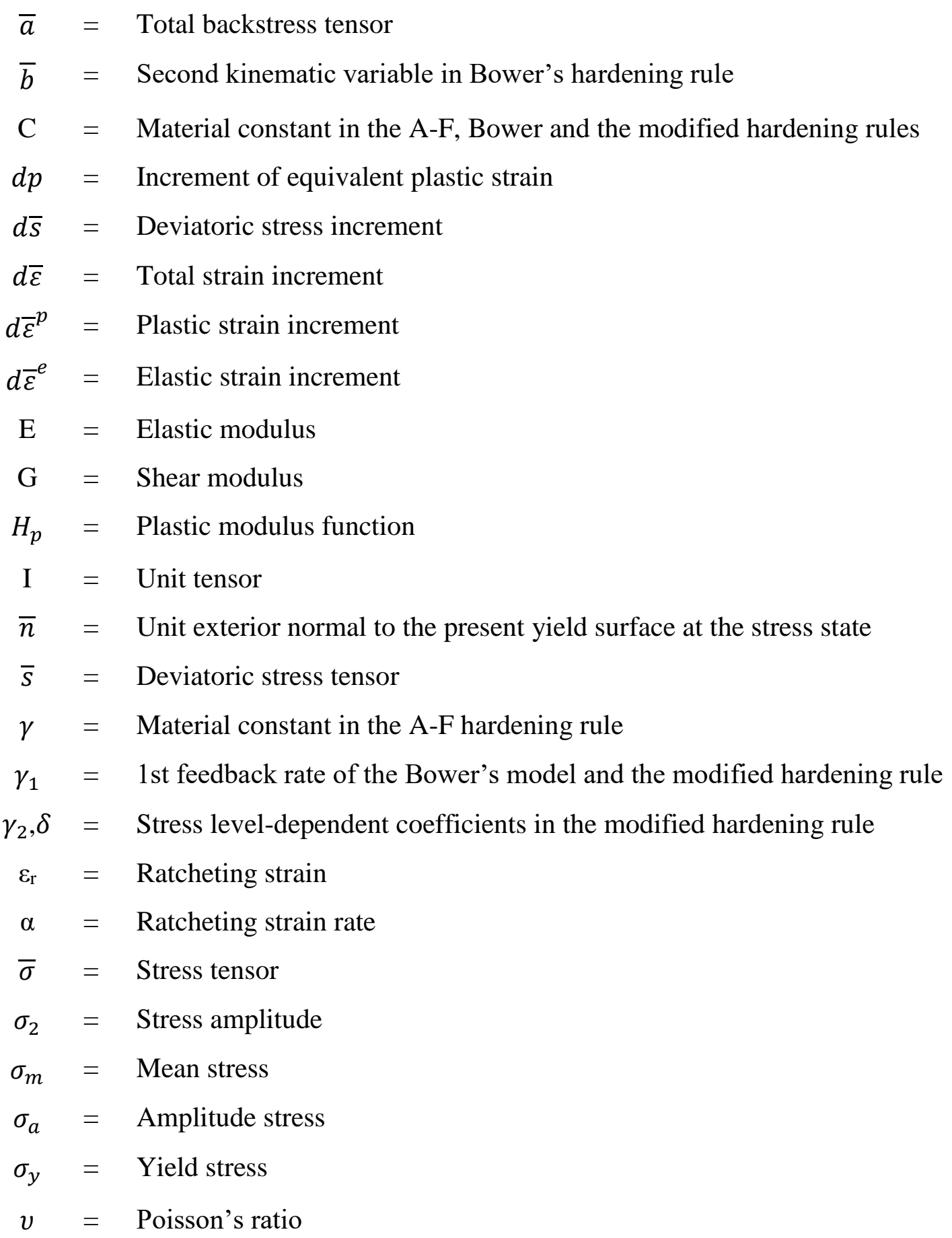




\section{CHAPTER 1}

\section{Problem Definition and Introduction}

\subsection{Problem Definition}

Ratcheting behavior is seen in all engineering materials subjected to cyclic loading with mean stress. Due to this ratcheting action, the estimated fatigue life of the component reduces, and the life of the material decreases from its estimated life span, so the ratcheting strain needs to be reduced as much as possible to increase component life.

\subsection{Introduction}

Engineering components in their service life undergo symmetric fatigue loading or asymmetric fatigue loading. Most fatigue damage is greatly influenced by mean stress. From deformation behavior perspective, application of mean stress under stress-controlled fatigue loading gives rise to ratcheting action, which results in accumulation of plastic strain during low cycle fatigue loading [1]. Ratcheting effect not only produces the large deformation but also the fatigue damage in the material; this reduces the life of material. Fatigue life of the material degrades due to the accumulation of ratcheting strain, as shown by the Coffin Mansion Relation. For the past few years, several experiments and simulations have been done to study the degradation of the material due to material nature and imposed stress parameters [2]. Hence in design and structural component assessments of a material, ratcheting-fatigue interaction is more significant due to ratcheting-fatigue failure of material due to cyclic stress loading on the material.

\subsection{Ratcheting Assessment}

The uniaxial ratcheting behavior of different steel materials were examined with different mean stress $\left(\sigma_{\mathrm{m}}\right)$ and different stress amplitude $\left(\sigma_{\mathrm{a}}\right)$ combinations at room temperature. Ratcheting strains at the different stages were investigated at various types of loading cycles. The schematic triphasic trend of ratcheting strain over stress cycles is shown in Fig. 1.1. 


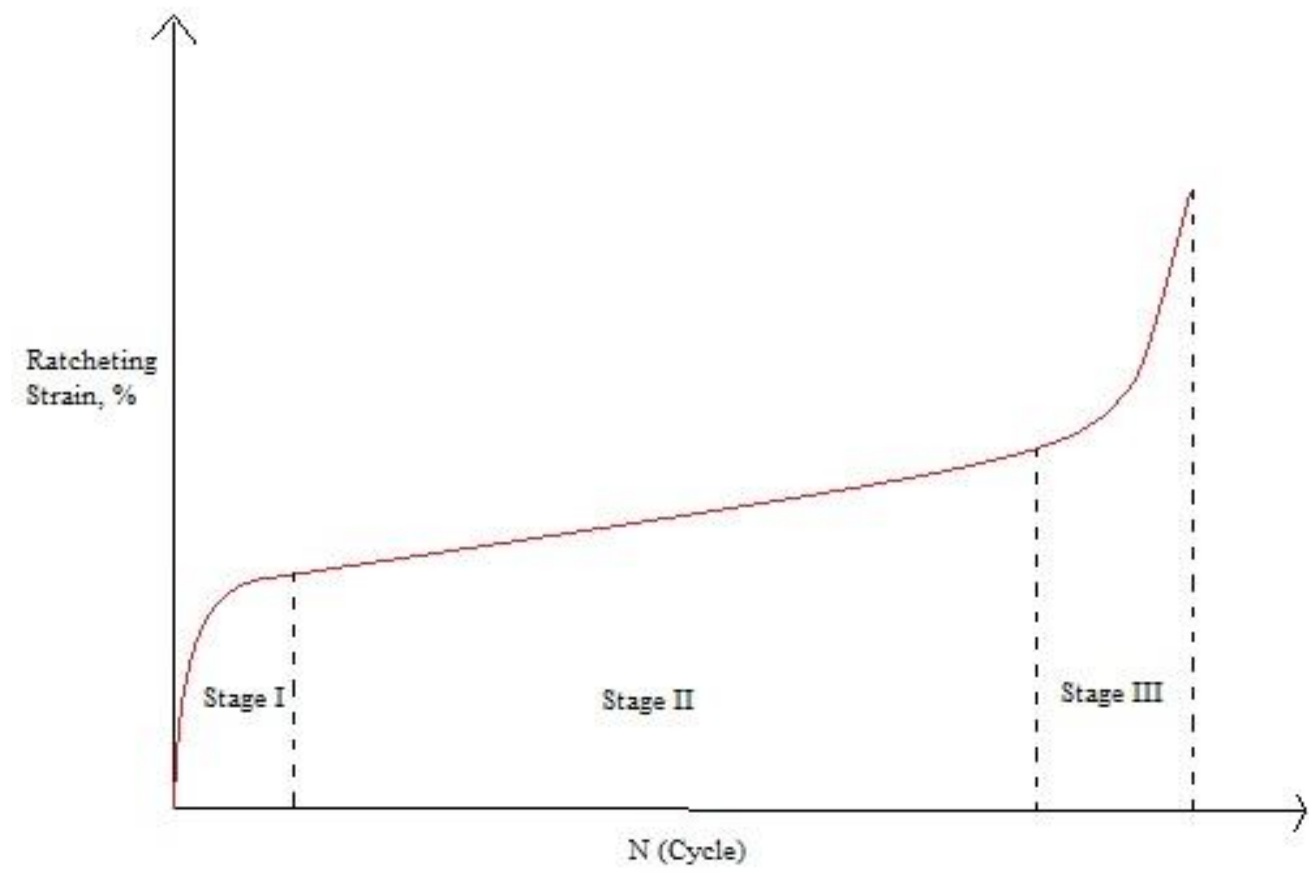

Fig.1.1: Schematic triphasic trend of ratcheting strain over a stress cycles [6]. 


\section{CHAPTER 2}

\section{Materials and Testing Method}

\subsection{Introduction}

The present thesis mainly focuses on uniaxial ratcheting behavior in stage II of different steels, such as interstitial free steel, 16MnR steel, SS304 stainless steel, 42CrMo steel alloy, SS316L steel, 20 CS steel, 1020 steel, SA 333 Gr6C-Mn steel, and HC340LA steel alloy.

\subsection{Experimental Ratcheting Test}

The ratcheting behavior of a material under uniaxial or multi-axial cyclic loading for different mean and amplitude stresses have been studied in many scholarly journals. The steel specimen used to study the ratcheting behavior is made into a solid cylindrical bar of $10 \mathrm{~mm}$ diameter and $30 \mathrm{~mm}$ gauge length. Before the material is cyclically tested, the tensile test is performed to study the fundamental properties of the material used for cyclic loadings, such as elastic modulus and yield strength. Ratcheting testing is carried out on electro-hydraulic servo fatigue testing machine. The mechanical loading process is performed in a controlled manner, and experimental data are gathered by the teststar control system that is attached to the testing machine [4]. The axial strain is measured using a strain extensometer of certain limit (i.e., 10\% - 50\%). The specimen geometry for ratcheting test is shown in Fig. 2.1.

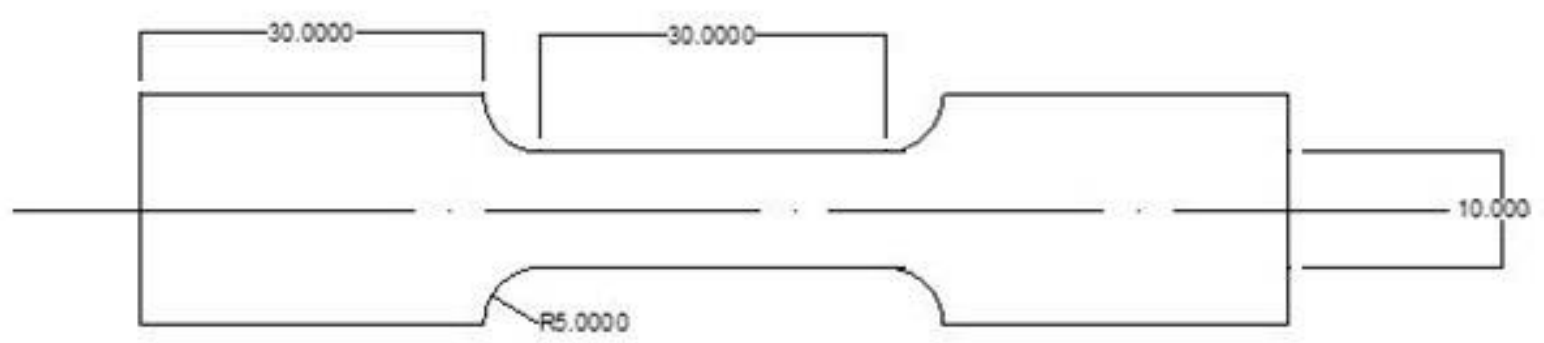

All dimensions are in millimeters ( $\mathrm{mm}$ )

Fig.2.1: Specimen geometry for ratcheting test [5]. 
Based on the test controlled, testing can be classified into two categories that are as follows (i) constant mean stress with varying stress amplitude (ii) constant stress amplitude with varying mean stress. An example of schematic loading path for ratcheting test as shown in Fig. 2.2.

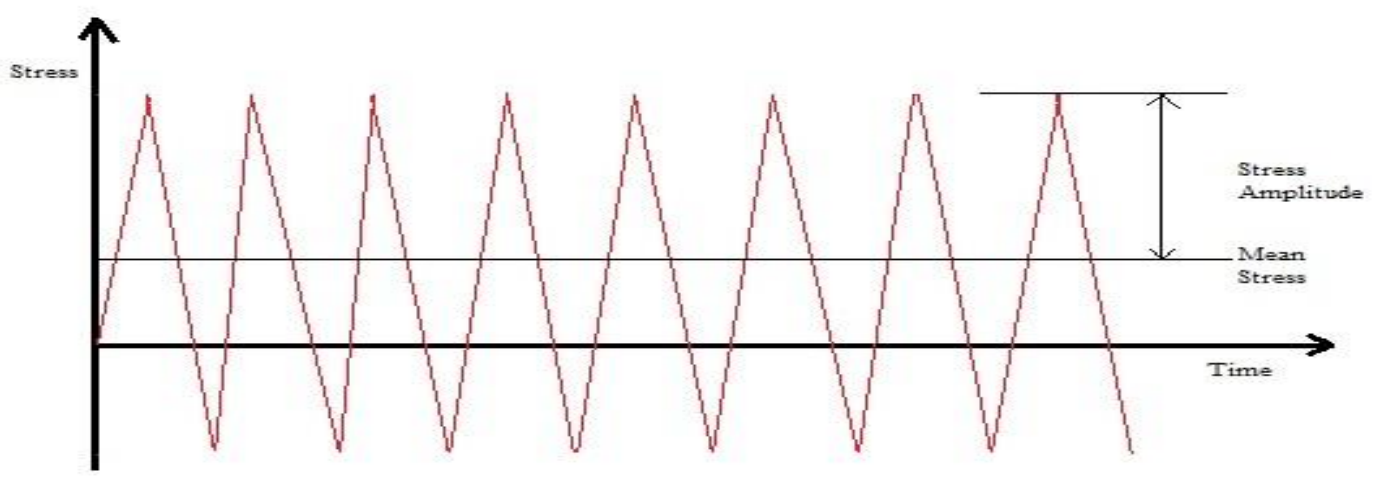

Fig.2.2: schematic loading path for ratcheting test [2].

Ratcheting stain $\left(\varepsilon_{\mathrm{r}}\right)$ is defined as the average of maximum and minimum strain obtained using extensometer and $\varepsilon_{\mathrm{r}}$ given by

$\varepsilon_{r}=\left(\varepsilon_{\max }+\varepsilon_{\min }\right) / 2$

From the Eq. 2.1, we can find the ratcheting rate $\mathrm{d} \varepsilon_{\mathrm{r}} / \mathrm{dN}$ after each cycle is calculated, where $\mathrm{N}$ is number of cycles. Ratcheting stain effect on fatigue life of the material is investigated by testing the material under uniaxial cyclic stress at room temperature with various mean stress and stress amplitude till the failure occurs. For example Table 2.1 shows the range of mean stress and stress amplitude to study the ratcheting behavior in interstitial free steel [2]. 
Table 2.1: Mean stress and stress amplitude for ratcheting test in interstitial free (IF) steel [2].

\begin{tabular}{|c|c|c|}
\hline Serial number & $\sigma_{m}(\mathrm{MPa})$ & $\sigma_{a}(\mathrm{MPa})$ \\
\hline 1 & 10 & $130,140,150$ \\
\hline 2 & 20 & $130,140,150$ \\
\hline 3 & 30 & $130,140,150$ \\
\hline
\end{tabular}

From the Table 2.1 it is clear that material is subjected to three different types of loading with constant stress amplitude (130,140and $150 \mathrm{MPa})$ and varying mean stress (10, 20 and $30 \mathrm{MPa})$.

\subsection{Accumulation of Ratcheting Strain}

The accumulation of ratcheting strain takes place when the material is subjected to asymmetric cyclic loading with some mean stress values. The nature of the hysteresis loop varies based on the level of imposed mean stress.

From the stress-strain curve for IF steel shown by k. Dutta et al., that with varying mean stress of 10, 20 and $30 \mathrm{MPa}$ and constant stress amplitude of $140 \mathrm{MPa}$ for 100 cycles, it is clear that the hysteresis loop shifts towards the positive plastic strain with the increase in applied mean stress. Plastic strain magnitude for the above figure with the mean stress of 10,20 and $30 \mathrm{MPa}$ is $3.6 \%$, $5.3 \%$ and $6.1 \%$. The similar experiment is performed for different steels and steel alloys with different mean stress and stress amplitude for the different number of cycles.

Ratcheting strain with that of number loading cycles for IF steel is shown in the Fig. 2.3. The increase in loading cycles will result in an increase in accumulation of ratcheting strain for any $\sigma_{\mathrm{m}}$ and $\sigma_{\mathrm{a}}$ combinations. 

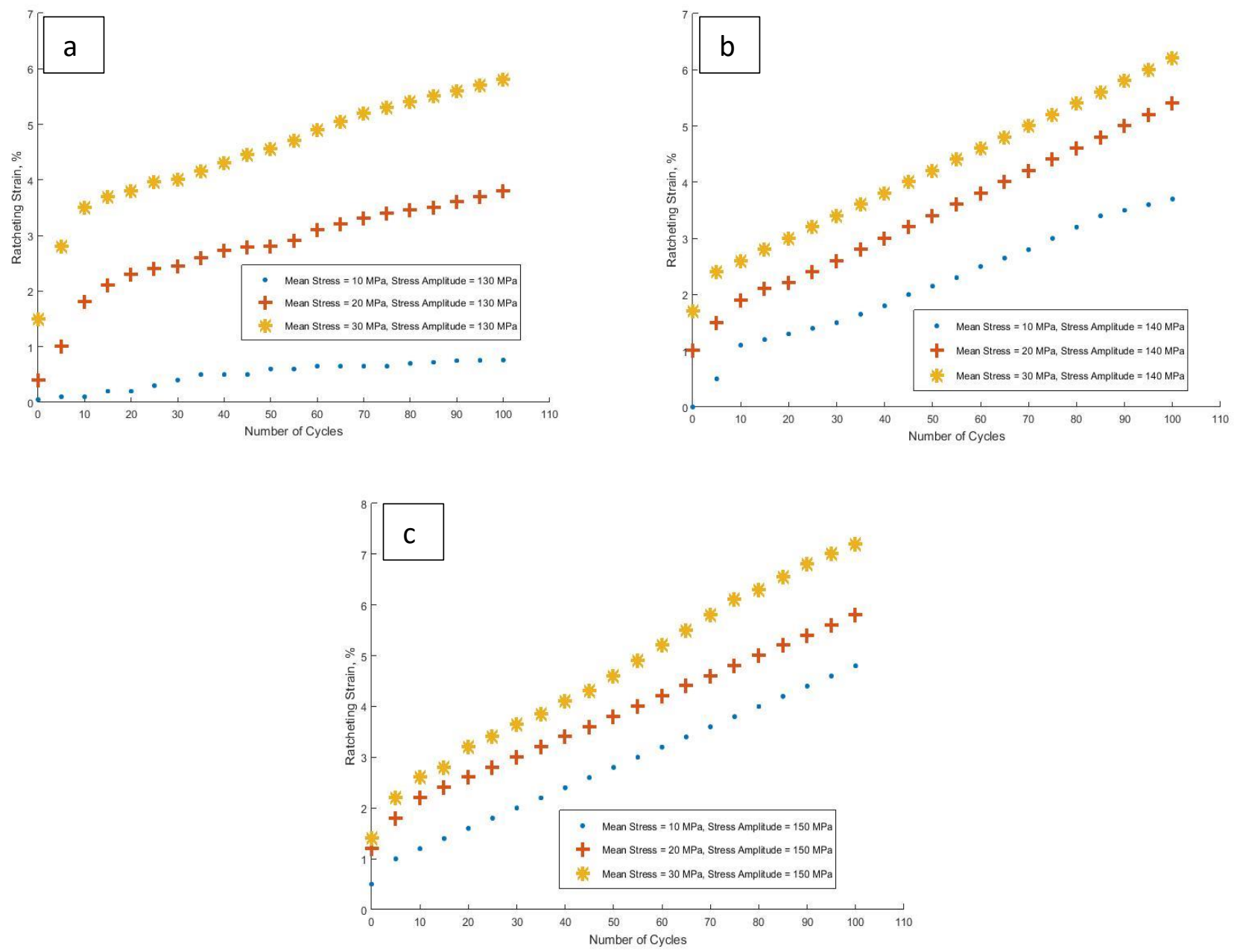

Fig. 2.3: Various ratcheting strains with 100 loading cycles for different mean stress and constant stress amplitudes of (a) $130 \mathrm{MPa}$ (b) $140 \mathrm{MPa}$ (c) $150 \mathrm{MPa}$ in IF steel [2].

From Fig. 2.3 it is clear that ratcheting strain increases with increases in applied mean stress and amplitude stress. Similarly, we can study the ratcheting behaviour of the material by keeping mean stress as constant and varying the stress amplitude as shown in Fig. 2.4. 


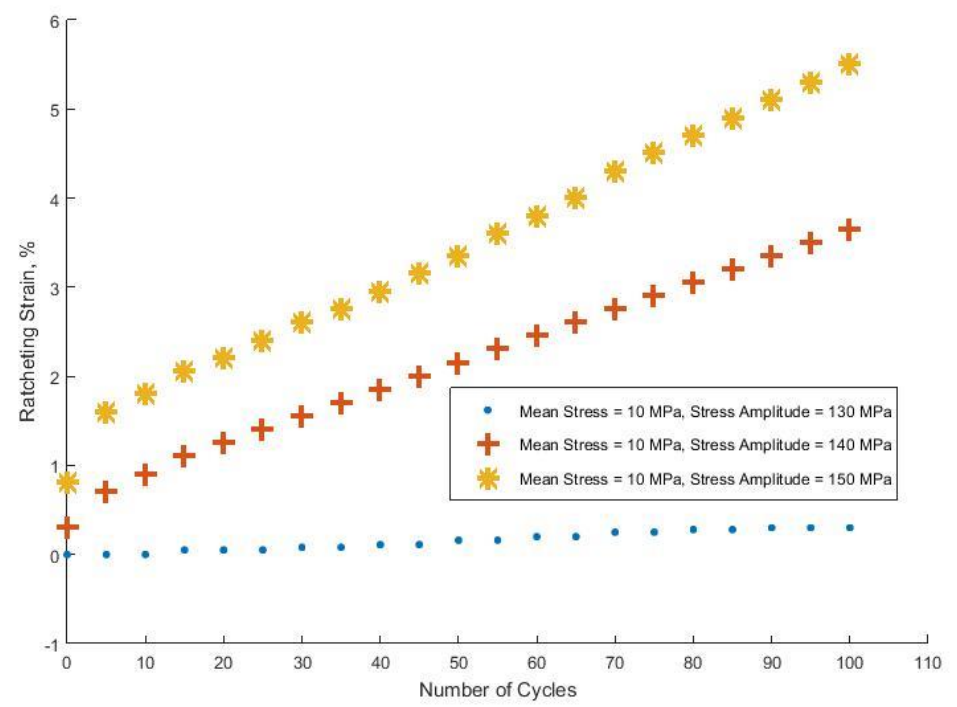

Fig. 2.4: Various ratcheting strains with 100 loading cycles for different stress amplitude and constant mean stress of $10 \mathrm{MPa}$ and varying stress amplitude of 130, 140 and $150 \mathrm{MPa}$ in IF steel [2]. 


\section{CHAPTER 3}

\section{Mathematical Models for Ratcheting Strain Prediction}

\subsection{Parametric triphasic ratcheting equation}

Accumulation of ratcheting strain over three stages of material lifespan is formulated [8]. The ratcheting response of different materials over a stress cycles $N_{f}$ is expressed as follows

$\varepsilon_{r}=\alpha\left(A\left(\frac{\ln N}{\ln N_{f}}+C\left(\frac{N}{N_{f}}-\frac{\ln N}{\ln N_{f}}\right)\right)+B^{2} \frac{\ln \left(1-\frac{N}{N_{f}}\right)}{\ln \frac{1}{N_{f}}}\right)$

where the coefficients $A, B, C$ and $\alpha$ are

$$
\begin{aligned}
& A=2 \ln \left(\frac{\sigma_{y}}{E}\right)^{-1} \\
& B=\ln \left(\frac{\Delta \sigma}{E}\right) \\
& C=\frac{1}{2}\left(1-\frac{\sigma_{m}}{\Delta \sigma}\right)^{\frac{1}{2 n}} \\
& \alpha=\left(\frac{\sigma_{u l t}}{\sigma_{y}}\right)^{n}
\end{aligned}
$$

From the equation above the term $\Delta \sigma$ is the stress range, $2 \sigma_{a}$. 
Eq. 3.1 represents the triphasic ratcheting strain accumulation over certain life cycles of the material as shown in the Fig. 3.1. This equation represents the three different stages of ratcheting strain rate. In stage I the ratcheting strain rate drops while in stage II it remains steady and in Stage III it is found that there is a sudden increase in ratcheting strain rate that leads to failure.

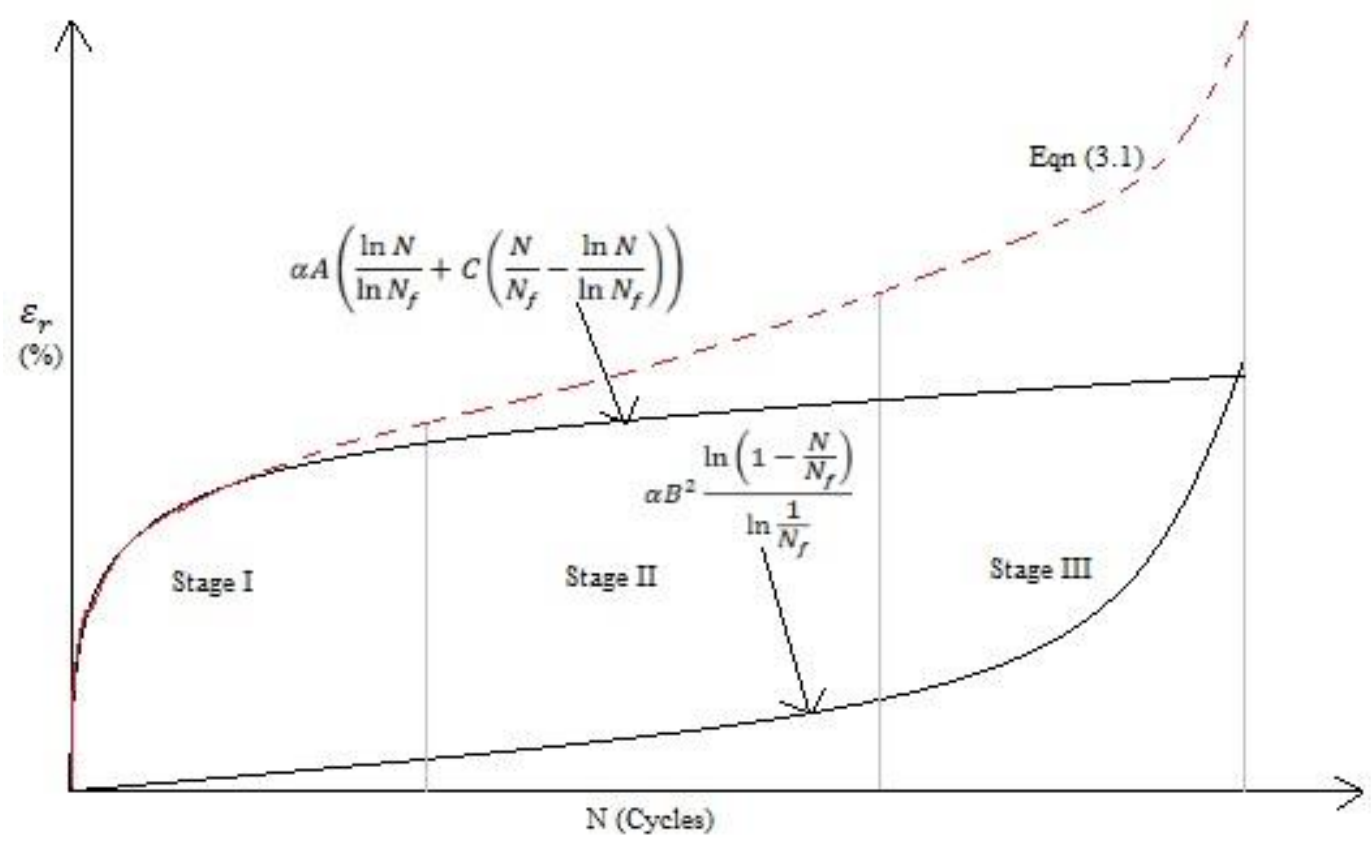

Fig. 3.1: Parametric triphasic ratcheting strain over $N_{f}[8]$.

\subsection{Hardening rule}

The theory of cyclic plasticity is based on the strain increment due to elastic and plastic strain components [17], and it can be represented as

$d \bar{\varepsilon}=d \bar{\varepsilon}^{e}+d \bar{\varepsilon}^{p}$

From hooks law, the elastic part is explained as

$\bar{\varepsilon}^{e}=\frac{\bar{\sigma}}{2 G}-\frac{v}{E}(\bar{\sigma} \cdot \bar{I}) \bar{I}$

Plastic part is defined as the

$d \bar{\varepsilon}^{p}=\frac{1}{H_{p}}(d \bar{s} \cdot \bar{n}) \bar{n}$ 
Where $d \bar{s}, H_{p}$ and $\bar{n}$ are deviatoric stress tensor increment, plastic modulus and normal vector. Deviatoric stress is expressed as

$\bar{S}=\bar{\sigma}-\frac{1}{3}(\bar{\sigma} \cdot \bar{I}) \bar{I}$

Yield surface remain unchanged during loading and unloading conditions. Von-Mises yielding criteria is used

$f\left(\bar{s}, \bar{a}, \sigma_{y}\right)=\frac{3}{2}(\bar{s}-\bar{a}) \cdot(\bar{s}-\bar{a})-\sigma_{y}^{2}=0$

Under the stressed plastic deformation, yield surface movement direction is dictated by the hardening rule.

A nonlinear hardening model is developed by Armstrong-Frederick [12] as

$d \bar{a}=C d \bar{\varepsilon}^{p}-\gamma \bar{a} d p$

where

$d p=\sqrt{d \bar{\varepsilon}^{p} \cdot d \bar{\varepsilon}^{p}}$

$C$ and $\gamma$ are material constants of strain-controlled uniaxial stress-strain hysteresis loop.

The first term in the Eq. (3.11) refers to strain hardening and second term is nonlinear trend in hardening rule. Plastic modulus function is defined as

$H_{p}=C-\gamma(\bar{a} \cdot \bar{n})$

The ratcheting response in A-F model was overestimating hence Bower modified A-F model to predict ratcheting strain rate and was defined as Bower's hardening rule

$d \bar{a}=C d \bar{\varepsilon}^{p}-\gamma_{1}(\bar{a}-\bar{b}) d p$

where

$d \bar{b}=\gamma_{2}(\bar{a}-\bar{b}) d p$ 
This rule consists of three variables $C, \gamma_{1}$ and $\gamma_{2}$ as material constant, first feedback rate to control the stress-strain hysteresis loop and second feedback rate to determine the ratcheting rate. But Bower's ratcheting rule experienced ratcheting arrest and premature plastic shakedown and hence it is limited by the number of cycles and not beyond the stage I.

Ahmadzadeh and Varvani-Farahani extended the bower's rule to study the ratcheting response of the material under long range of loading cyclic in stage I and II and it is named as A-V model.

$d \bar{a}=C d \bar{\varepsilon}^{p}-\gamma_{1}(\bar{a}-\delta \bar{b}) d p$

$d \bar{b}=\gamma_{2}(\bar{a}-\bar{b}) d p$

A new term $\delta$ is introduced to avoid ratcheting arrest in stage II as shown in fig. 3.3. The coefficient $\gamma_{2}$ and $\delta$ is expressed as

$\gamma_{2}=\sqrt{\sigma_{m}}\left(\sigma_{a}-\sigma_{y}\right)^{\rho_{1}}+K\left(\sigma_{a}-\sigma_{y}\right)^{\rho_{2}}$

$\delta=1-F e^{\lambda \sigma_{a}}$

where $\rho_{1}$ and $\rho_{2}$ and $K$ are material constants. $\rho_{1}$ relates to mean stress level and $\rho_{2}$ remains unchanged for steels. 


\section{CHAPTER 4}

\section{Results and Discussion}

\subsection{Introduction}

This thesis focuses only on ratcheting behaviour of different steels at stage II due to uniaxial loading. Ratcheting strain rate is calculated using the tangent of ratcheting strain and loading cycle graph as shown in Fig. 4.1.

Ratcheting strain rate $=$ Angular tangent $(a / b)=d \varepsilon_{r} / d N=\alpha$

Hence from the above, the formula ratcheting strain rate for different material at different mean stress and stress amplitude is obtained.
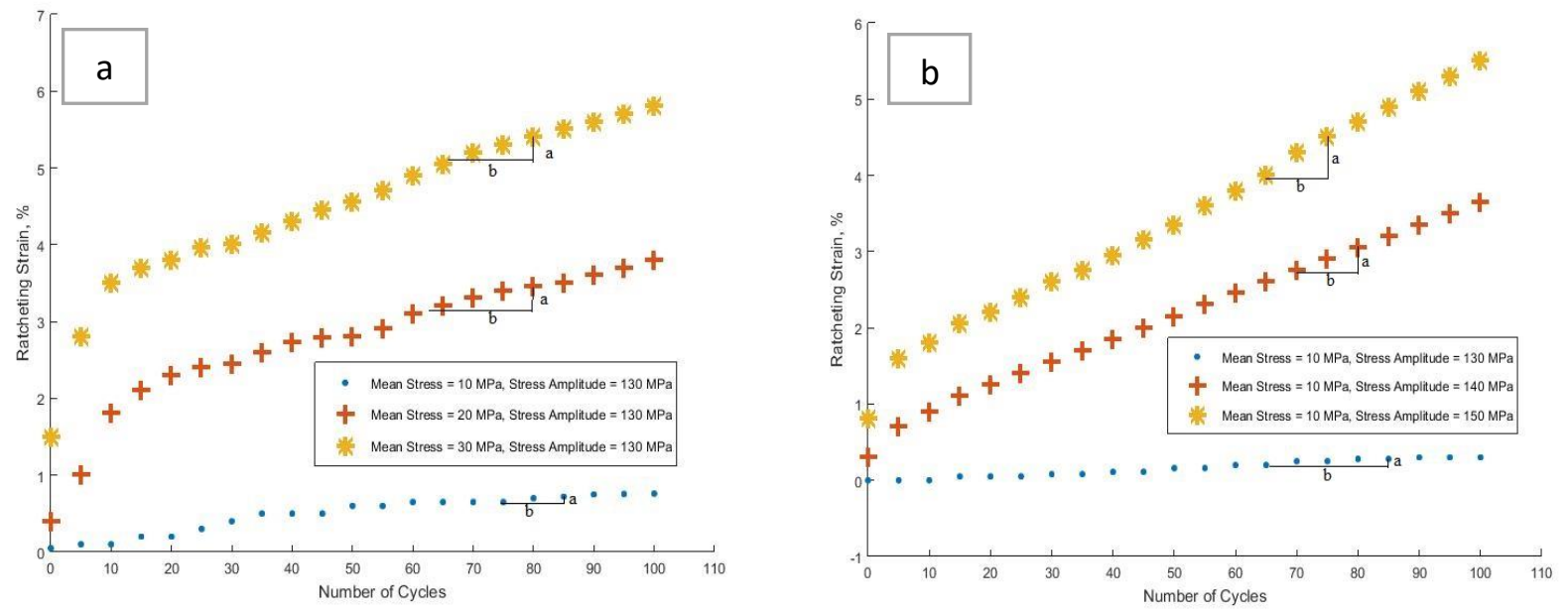

Fig. 4.1: Slope of a /b represent the ratcheting stain rate for IF steel for (a) constant stress amplitude of $130 \mathrm{MPa}$ with varying mean stress (b) constant mean stress of $10 \mathrm{MPa}$ with varying stress amplitude [2].

\subsection{Ratcheting strain rate at stage II}

From the above value of ratcheting strain rate in different steel materials, I just plotted different sets of graphs for ratcheting strain rate vs. varying mean stress at constant stress amplitude 
conditions and ratcheting strain rate vs. varying stress amplitude at constant mean stress conditions.
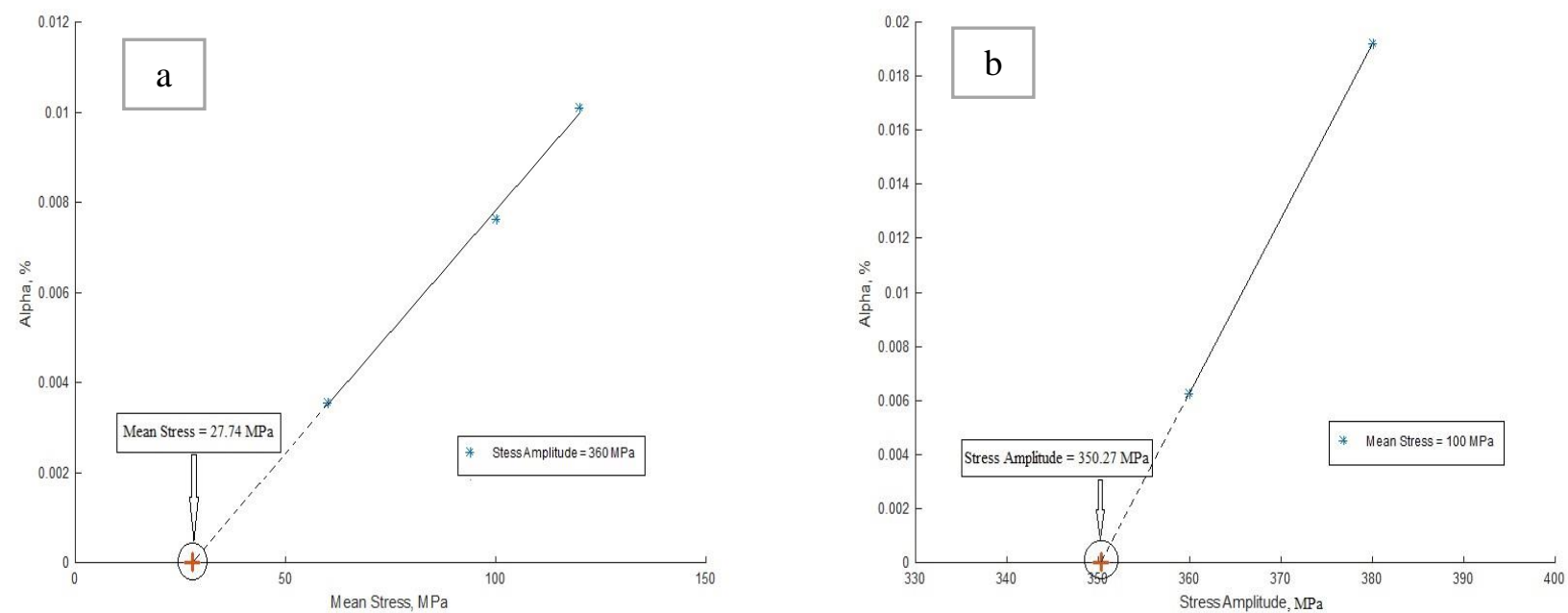

Fig. 4.2: (a) Ratcheting strain rate vs. mean stress at constant stress amplitude of $360 \mathrm{MPa}$ (b) ratcheting strain rate vs. stress amplitude at constant mean stress of $100 \mathrm{MPa}$ is plotted for $16 \mathrm{MnR}$ steel.
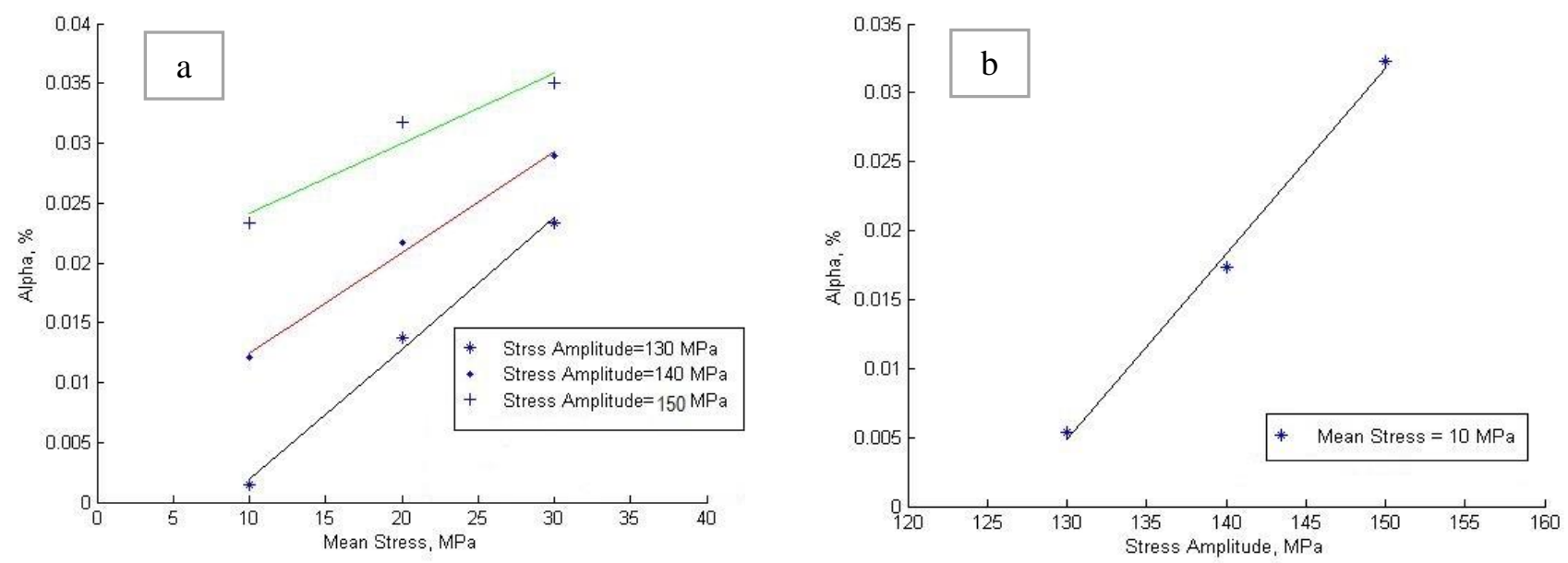

Fig. 4.3: (a) Ratcheting strain rate vs. mean stress at constant stress amplitude of 130, 140 and $150 \mathrm{MPa}$ (b) ratcheting strain rate vs. stress amplitude at constant mean stress of $10 \mathrm{MPa}$ is plotted for interstitial free steel. 

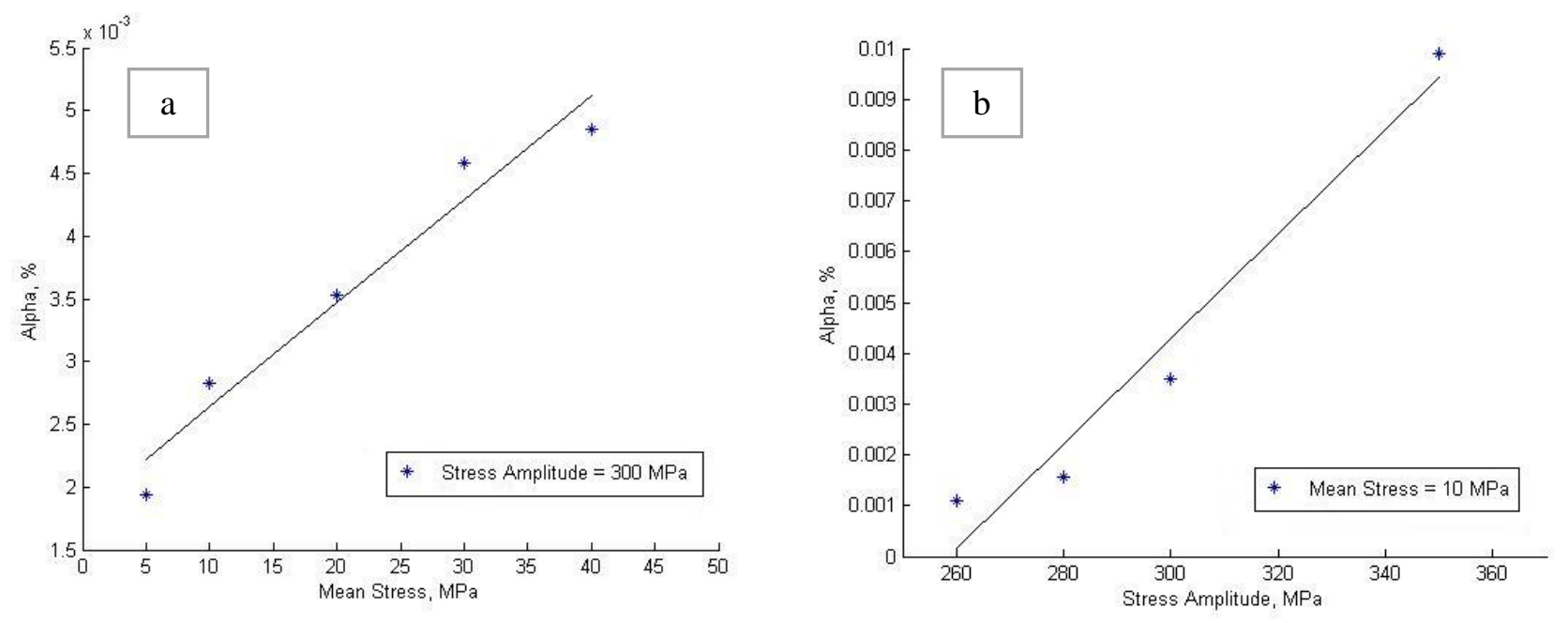

Fig. 4.4: (a) Ratcheting strain rate vs. mean stress at constant stress amplitude of $300 \mathrm{MPa}$ (b) ratcheting strain rate vs. stress amplitude at constant mean stress of $10 \mathrm{MPa}$ is plotted for SS304.
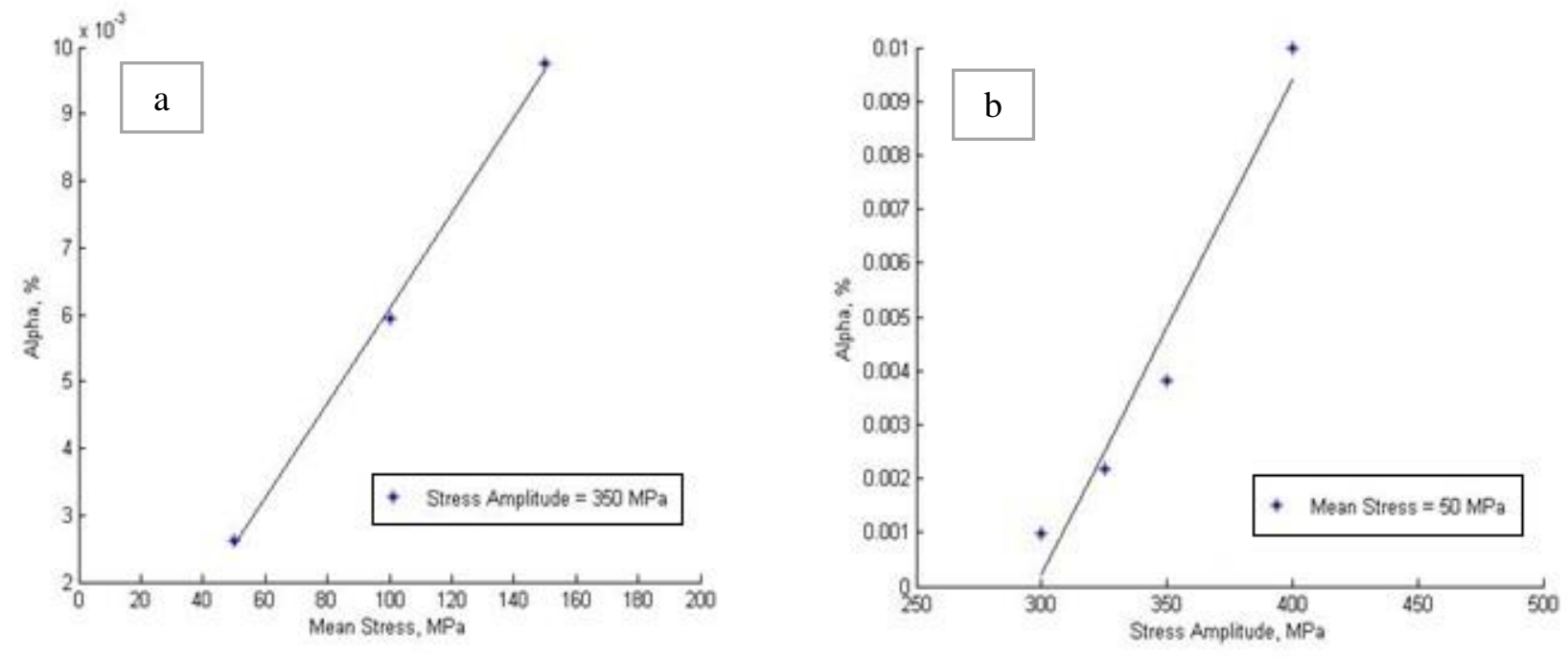

Fig. 4.5: (a) Ratcheting strain rate vs. mean stress at constant stress amplitude of $350 \mathrm{MPa}$ (b) ratcheting strain rate vs. stress amplitude at constant mean stress of $50 \mathrm{MPa}$ is plotted for 42CrMo steel. 

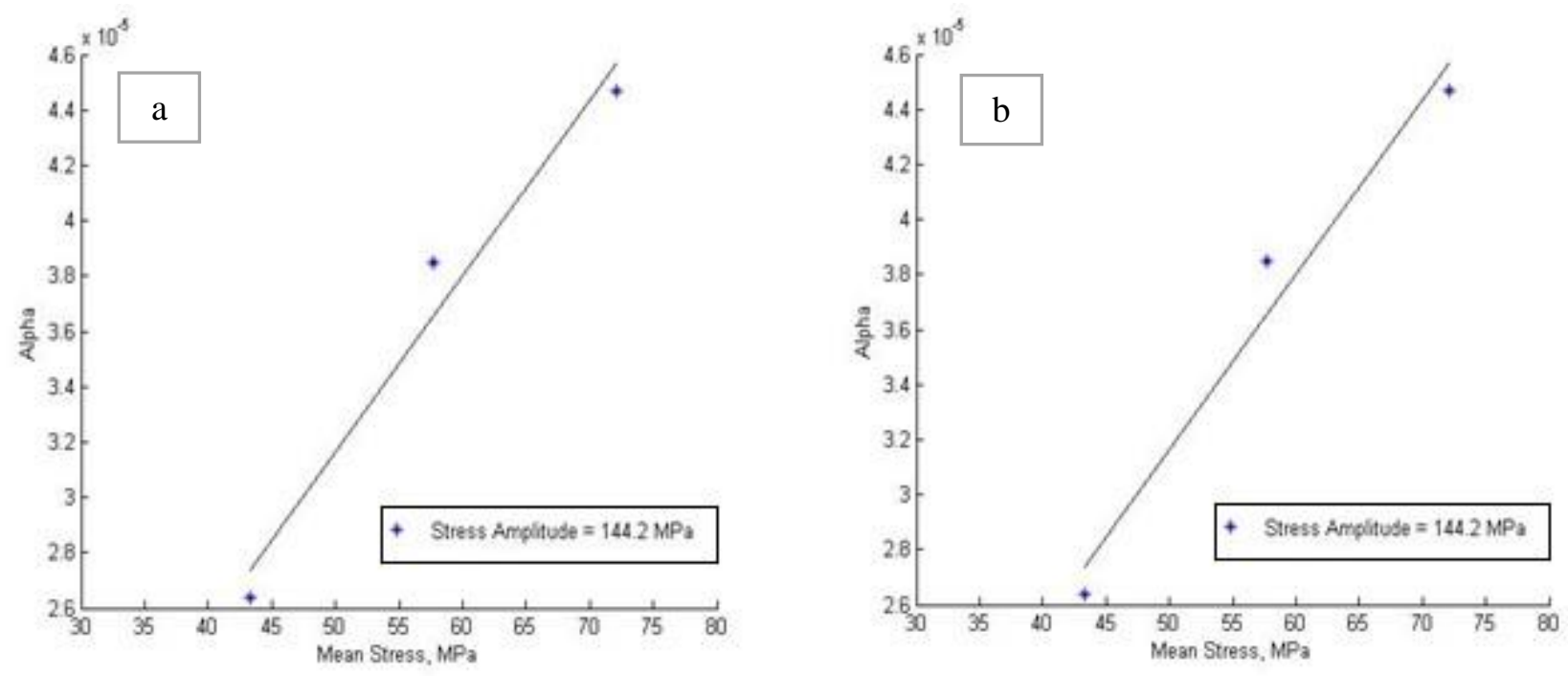

Fig. 4.6: (a) Ratcheting strain rate vs. mean stress at constant stress amplitude of 144.2 MPa (b) ratcheting strain rate vs. stress amplitude at constant mean stress of $28.84 \mathrm{MPa}$ is plotted for titanium-stabilized steel.
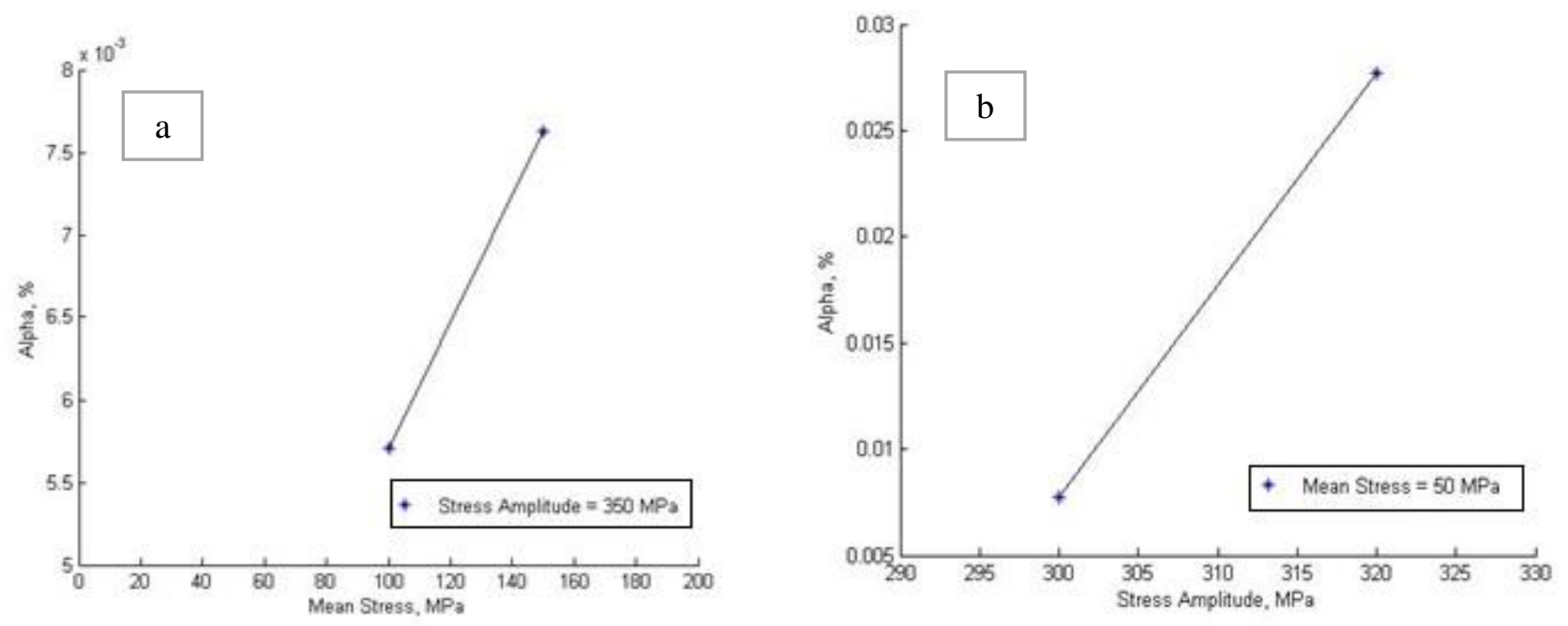

Fig. 4.7: (a) Ratcheting strain rate vs. mean stress at constant stress amplitude of $350 \mathrm{MPa}$ is plotted for $42 \mathrm{CrMo}$ steel (b) ratcheting strain rate vs. stress amplitude at constant mean stress of $50 \mathrm{MPa}$ is plotted for 1020 steel. 

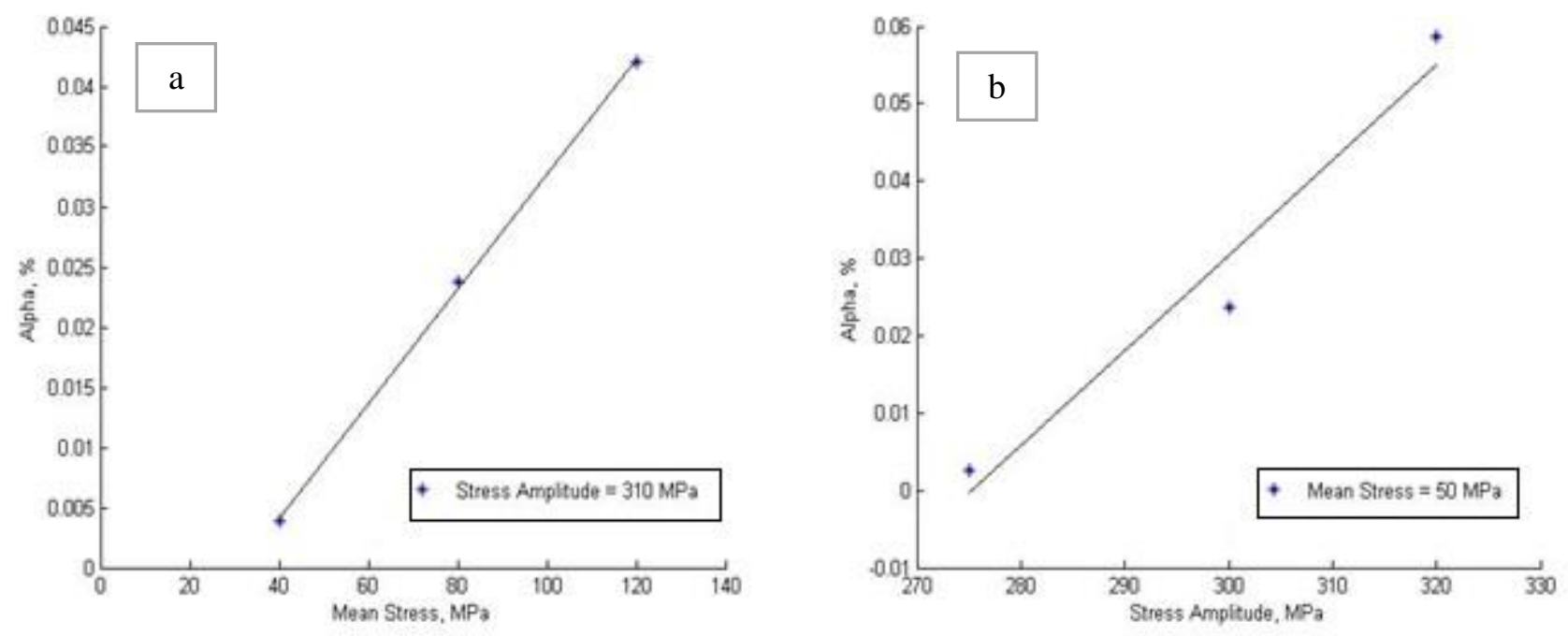

Fig. 4.8: (a) Ratcheting strain rate vs. mean stress at constant stress amplitude of $310 \mathrm{MPa}$ is plotted for SA 333 Gr6C-Mn steel (b) ratcheting strain rate vs. stress amplitude at constant mean stress of $50 \mathrm{MPa}$ is plotted for 20CS steel.
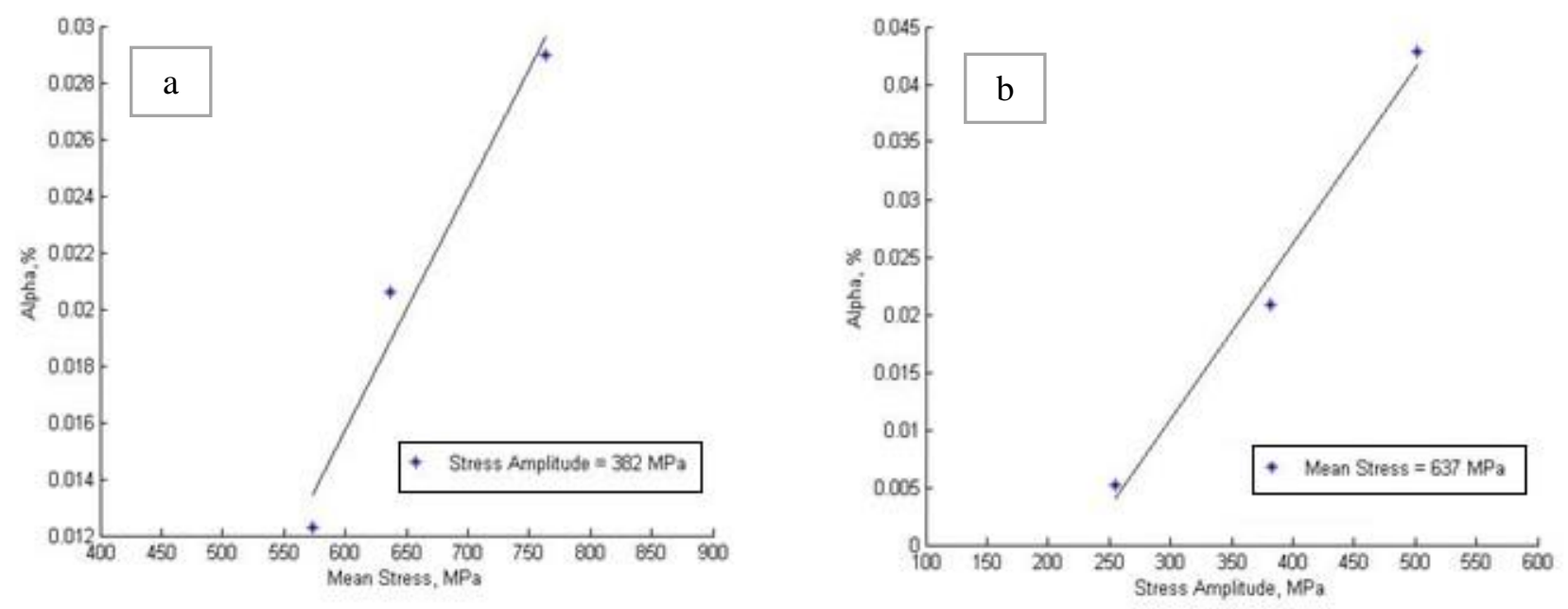

Fig. 4.9: (a) Ratcheting strain rate vs. mean stress at constant stress amplitude of $382 \mathrm{MPa}$ (b) ratcheting strain rate vs. stress amplitude at constant mean stress of $637 \mathrm{MPa}$ is plotted for X13CrMnMoN18-14-3 high nitrogen steel. 

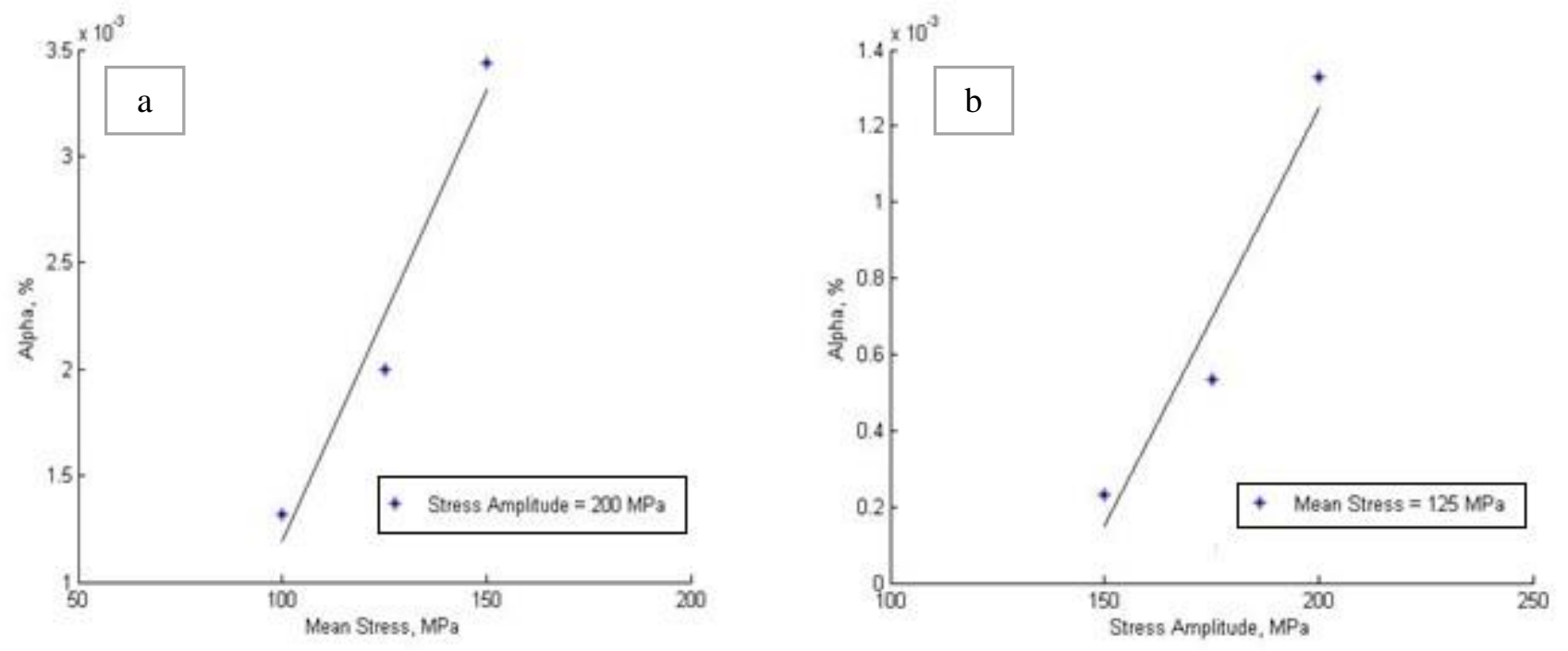

Fig. 4.10: (a) Ratcheting strain rate vs. mean stress at constant stress amplitude of $200 \mathrm{MPa}$ (b) ratcheting strain rate vs. stress amplitude at constant mean stress of $125 \mathrm{MPa}$ is plotted for Z2CND18-12N steel.
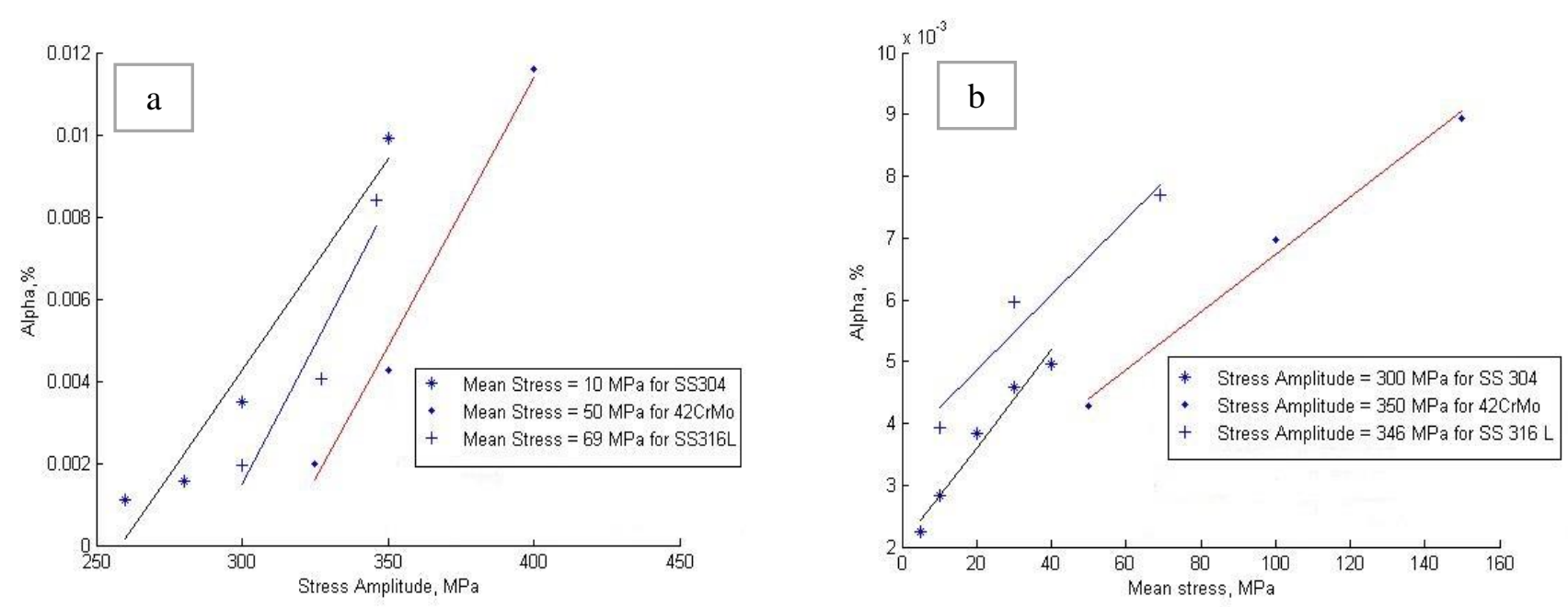

Fig. 4.11: (a) Ratcheting strain rate vs. mean stress at constant stress amplitude and (b) ratcheting strain rate vs. stress amplitude at constant mean stress is plotted for three different steel. 

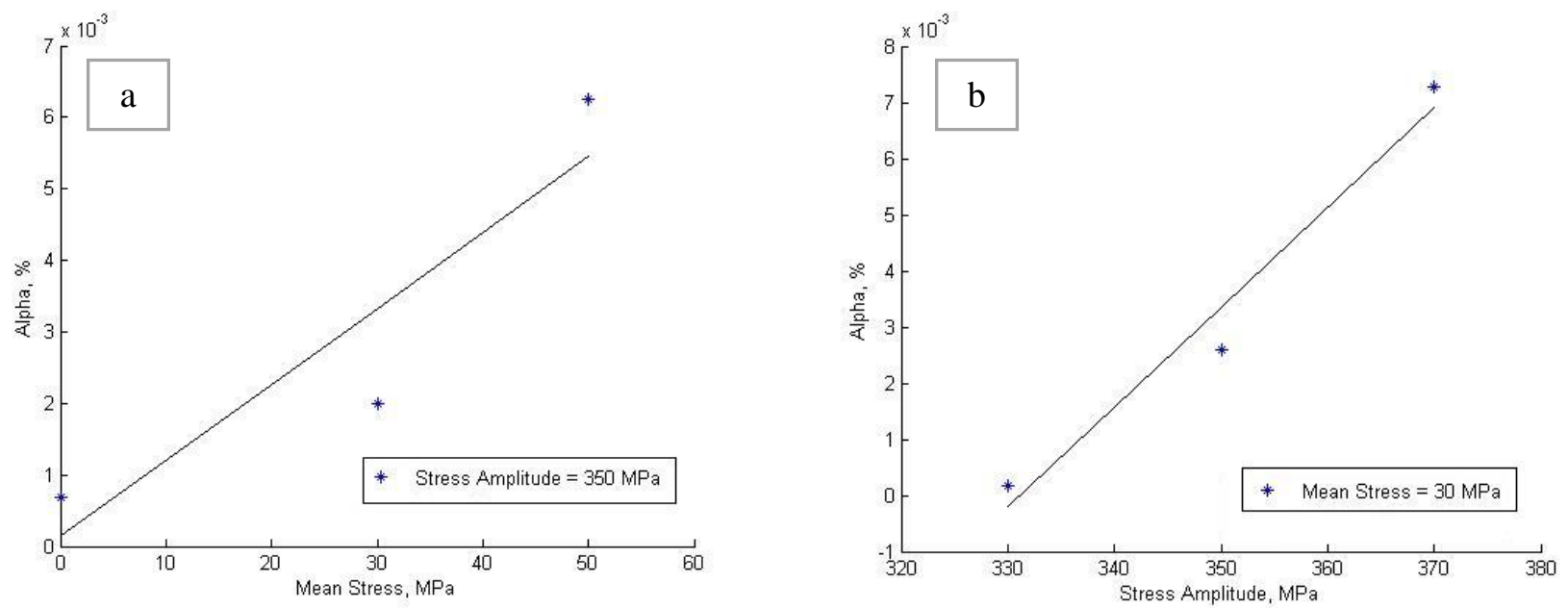

Fig. 4.12: (a) Ratcheting strain rate vs. mean stress at constant stress amplitude of $350 \mathrm{MPa}$ (b) ratcheting strain rate vs. stress amplitude at constant mean stress of $30 \mathrm{MPa}$ is plotted for HC340LA steel.
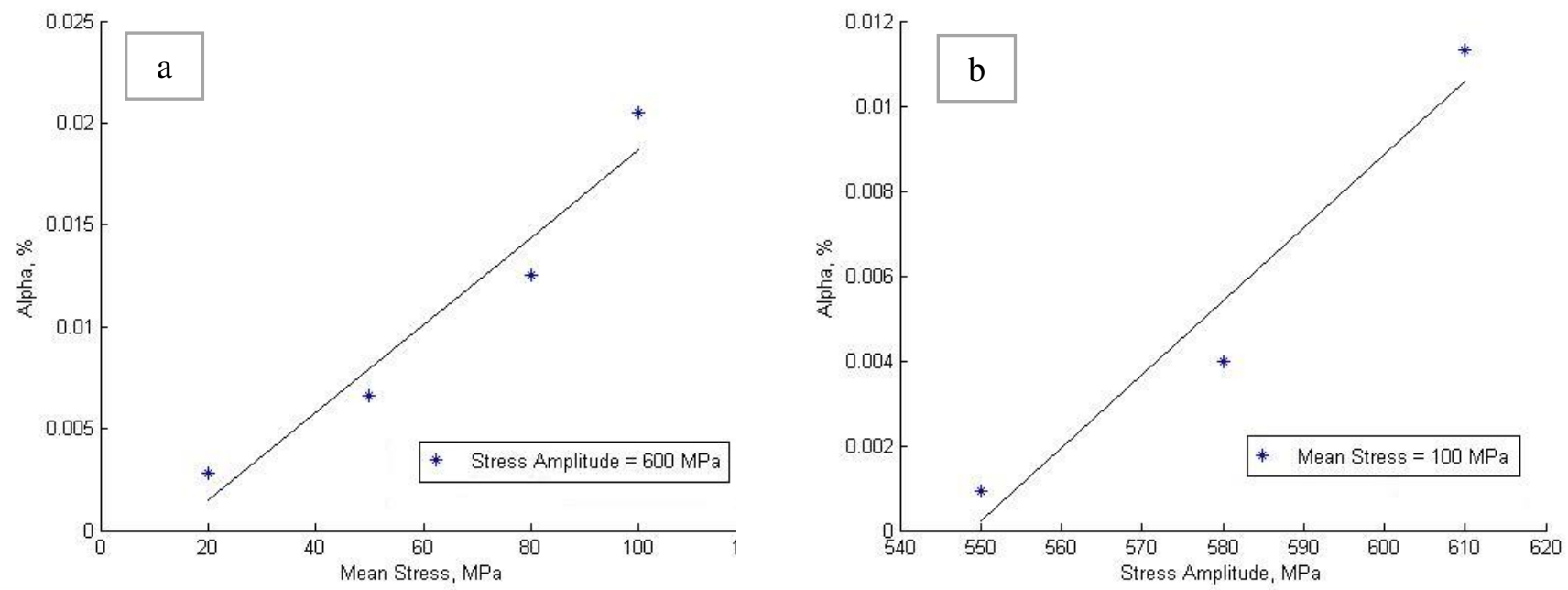

Fig. 4.13: (a) Ratcheting strain rate vs. mean stress at constant stress amplitude of $600 \mathrm{MPa}$ (b) ratcheting strain rate vs. stress amplitude at constant mean stress of $100 \mathrm{MPa}$ is plotted for HC340LA steel. 

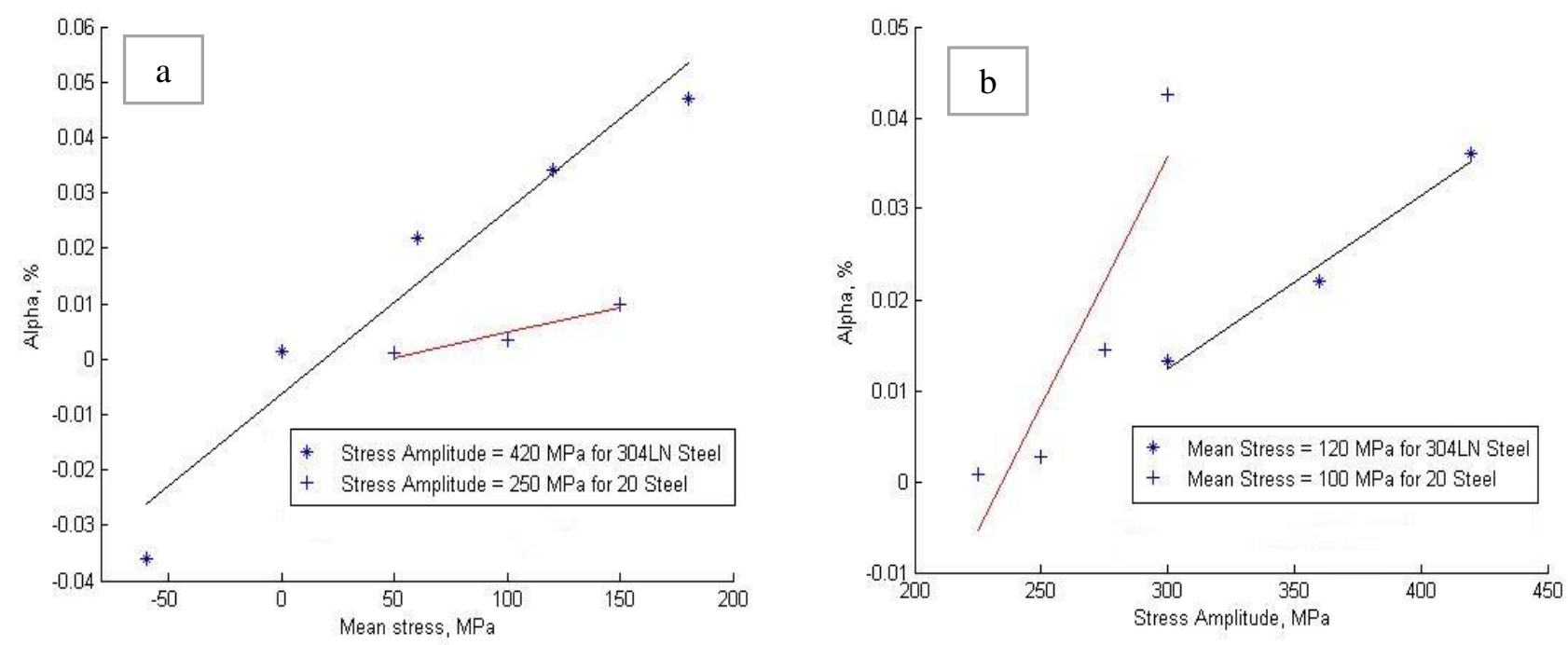

Fig. 4.14: (a) Ratcheting strain rate vs. mean stress at constant stress amplitude and (b) ratcheting strain rate vs. stress amplitude at constant mean stress of is plotted for 304LN Stainless steel and 20 Steel.

Linear fit line is drawn in for the plots shown in Fig. 4.2 to 4.14. These lines are generated using a linear equation.

$y=m x+c$

Slope $m$ and $y$-intercept $c$ are obtained from the above graphs using Matlab coding.

Using Eq. 4.2, we can find the value of mean stress and stress amplitude at zero ratcheting strain rate. The list of mean stress and stress amplitude at zero ratcheting stain rate as shown in Table 4.1. 
Table 4.1: Slope, y-intercept, mean stress and stress amplitude values at zero ratcheting strain for different steels.

\begin{tabular}{|c|c|c|c|c|}
\hline \multirow{2}{*}{ Material } & \multirow{2}{*}{$\begin{array}{c}\text { Slope from the } \\
\text { linear equation } \\
\qquad m\end{array}$} & \multirow{2}{*}{$\begin{array}{l}\text { Y-intercepts } \\
\text { from the linear } \\
\text { equation } c\end{array}$} & \multicolumn{2}{|c|}{ Zero ratcheting strain rate $(\alpha=0)$} \\
\hline & & & $\begin{array}{c}\text { Mean Stress } \\
\left(\sigma_{\mathrm{m}}\right), \mathrm{MPa}\end{array}$ & $\begin{array}{c}\text { Stress } \\
\text { Amplitude }\left(\sigma_{\mathrm{a}}\right), \\
\mathrm{MPa}\end{array}$ \\
\hline \multirow{2}{*}{ 16MnR Steel } & 0.00010814 & -0.003 & 27.74 & 360 \\
\hline & 0.000646 & -0.22628 & 100 & 350.27 \\
\hline \multirow{4}{*}{$\begin{array}{c}\text { Interstitial Free } \\
\text { Steel }\end{array}$} & 0.0005845 & 0.0183133 & -31.33 & 150 \\
\hline & 0.000841 & 0.0040567 & -4.823 & 140 \\
\hline & 0.001093 & -0.0090133 & 8.25 & 130 \\
\hline & 0.001346 & -0.1701133 & 10 & 126.38 \\
\hline \multirow{2}{*}{ SS304 } & 0.000053467 & 0.002277156 & -42.59 & 300 \\
\hline & 0.0001405 & -0.0372244 & 10 & 264.94 \\
\hline \multirow{2}{*}{ 42CrMo Steel } & 0.0000712 & -0.0010167 & 14.28 & 350 \\
\hline & 0.000091987 & -0.02738 & 50 & 297.65 \\
\hline
\end{tabular}




\begin{tabular}{|c|c|c|c|c|}
\hline \multirow{2}{*}{ Material } & \multirow{2}{*}{$\begin{array}{c}\text { Slope from the } \\
\text { linear equation } \\
m\end{array}$} & \multirow{2}{*}{$\begin{array}{l}\text { Y-intercepts } \\
\text { from the linear } \\
\text { equation } c\end{array}$} & \multicolumn{2}{|c|}{ Zero ratcheting strain rate $(\alpha=0)$} \\
\hline & & & $\begin{array}{c}\text { Mean Stress } \\
\left(\sigma_{\mathrm{m}}\right), \mathrm{MPa}\end{array}$ & $\begin{array}{c}\text { Stress } \\
\text { Amplitude }\left(\sigma_{a}\right) \\
\text { MPa }\end{array}$ \\
\hline \multirow{2}{*}{$\begin{array}{c}\text { Titanium- } \\
\text { Stabilized Free } \\
\text { Steel }\end{array}$} & $0.63454 \mathrm{E}-6$ & $-0.0675 \mathrm{E}-6$ & 0.106 & 144.2 \\
\hline & 0.000018294 & -0.0028023 & 28.84 & 153.18 \\
\hline $\begin{array}{c}\text { 42CrMo Steel } \\
\text { Alloy }\end{array}$ & 0.0000384 & 0.00187 & -48.70 & 350 \\
\hline 1020 Steel Alloy & 0.009985 & -0.29182 & 50 & 292.25 \\
\hline 20CS Steel & 0.00122697 & -0.337712 & 50 & 275.24 \\
\hline $\begin{array}{c}\text { SA333Gr6C-Mn } \\
\text { Steel }\end{array}$ & 0.00047637 & -0.01488 & 31.236 & 310 \\
\hline \multirow{2}{*}{$\begin{array}{c}\text { X13CrMnMoN18- } \\
\text { 14-3 High } \\
\text { Nitrogen Steel }\end{array}$} & 0.00015242 & -0.0349142 & 637 & 229.06 \\
\hline & 0.00008443 & -0.0349217 & 413.617 & 382 \\
\hline \multirow{2}{*}{$\begin{array}{l}\text { Z2CND18-12N } \\
\text { Steel }\end{array}$} & 0.0000424 & -0.0030467 & 71.86 & 200 \\
\hline & 0.00002194 & -0.0031408 & 125 & 142.828 \\
\hline \multirow{2}{*}{ SS304 } & 0.00010297 & -0.0266204 & 10 & 258.525 \\
\hline & 0.0000827085 & 0.00181092 & -21.89 & 300 \\
\hline
\end{tabular}




\begin{tabular}{|c|c|c|c|c|}
\hline \multirow{2}{*}{ Material } & \multirow{2}{*}{$\begin{array}{c}\text { Slope from the } \\
\text { linear equation } \\
m\end{array}$} & \multirow{2}{*}{$\begin{array}{l}\text { Y-intercepts } \\
\text { from the linear } \\
\text { equation } c\end{array}$} & \multicolumn{2}{|c|}{ Zero ratcheting strain rate $(\alpha=0)$} \\
\hline & & & $\begin{array}{l}\text { Mean Stress } \\
\left(\sigma_{\mathrm{m}}\right), \mathrm{MPa}\end{array}$ & $\begin{array}{c}\text { Stress } \\
\text { Amplitude }\left(\sigma_{a}\right), \\
\operatorname{MPa}\end{array}$ \\
\hline \multirow{2}{*}{ 42CrMo Steel } & 0.000130686 & -0.0408757 & 50 & 312.77 \\
\hline & 0.00004654 & 0.00161267 & -34.65 & 350 \\
\hline \multirow{2}{*}{ SS316L } & 0.000136186 & -0.03936339 & 69 & 289.04 \\
\hline & 0.00060922065 & 0.003650165 & -5.91189 & 346 \\
\hline \multirow{4}{*}{$\begin{array}{c}\text { HC340LA Steel } \\
\text { Alloy }\end{array}$} & 0.0001776 & -0.05881067 & 30 & 331.14 \\
\hline & 0.0001727 & -0.0947533 & 100 & 548.66 \\
\hline & 0.000106079 & 0.00014789 & -1.39 & 350 \\
\hline & 0.0002143395 & -0.002777966 & 12.968 & 600 \\
\hline \multirow{2}{*}{$\begin{array}{c}\text { 30LN Stainless } \\
\text { Steel }\end{array}$} & 0.0003427167 & -0.007489 & 21.85 & 420 \\
\hline & 0.000190083 & -0.0452933 & 120 & 238.28 \\
\hline \multirow{2}{*}{20 Steel } & 0.000089 & -0.0041 & 46.07 & 250 \\
\hline & 0.00054816 & -0.12876699 & 100 & 234.907 \\
\hline
\end{tabular}


From the Table 4.1 for zero ratcheting strain rate we obtain the corresponding mean stress and stress amplitude for different steel materials using the linear equation generated from the Fig. 4.2 to 4.14. The slope, $\mathrm{m}$ and $\mathrm{y}$-intercept, $\mathrm{c}$ values are obtained using Matlab coding. Hence by loading the material using these mean stress and stress amplitude we can arrest the ratcheting or reduce ratcheting up to the large extent in the material. Hence, finally the material life can be increased.

\subsection{Mean and amplitude stress relations}

Materials are used to steady cyclic loading subjected deformation; hence the material response is studied with the help of applied mean stress and stress amplitude subjected to loading cycles. Two dimensions $\mathrm{XY}$ graph is plotted with stress amplitude/yield stress as $\mathrm{X}$ component and mean stress/yield stress as Y component. An exponential curve is drawn using Matlab coding and the corresponding equation is obtained for different steel material as listed in Table 4.2.

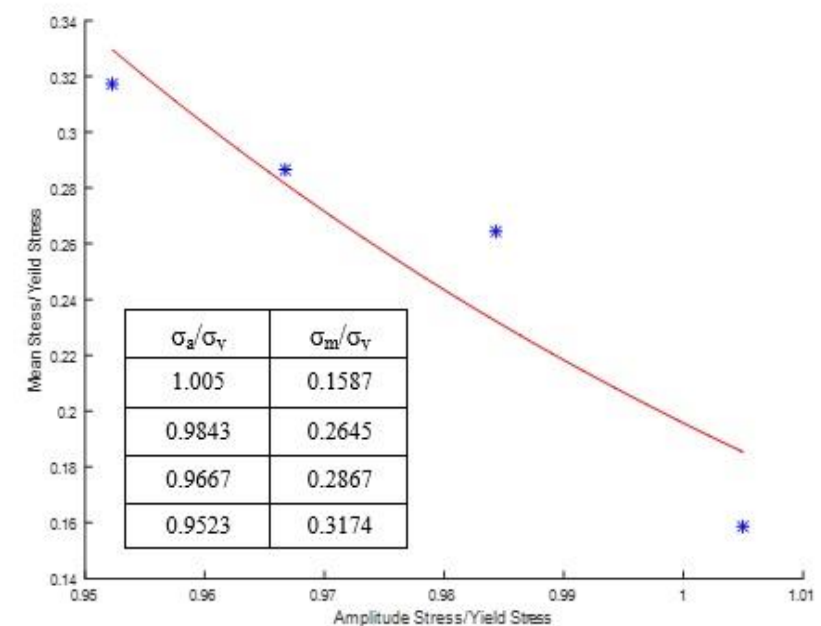

Fig. 4.15: Mean and amplitude stress relation for $16 \mathrm{MnR}$ steel at yield stress of $378 \mathrm{MPa}$.

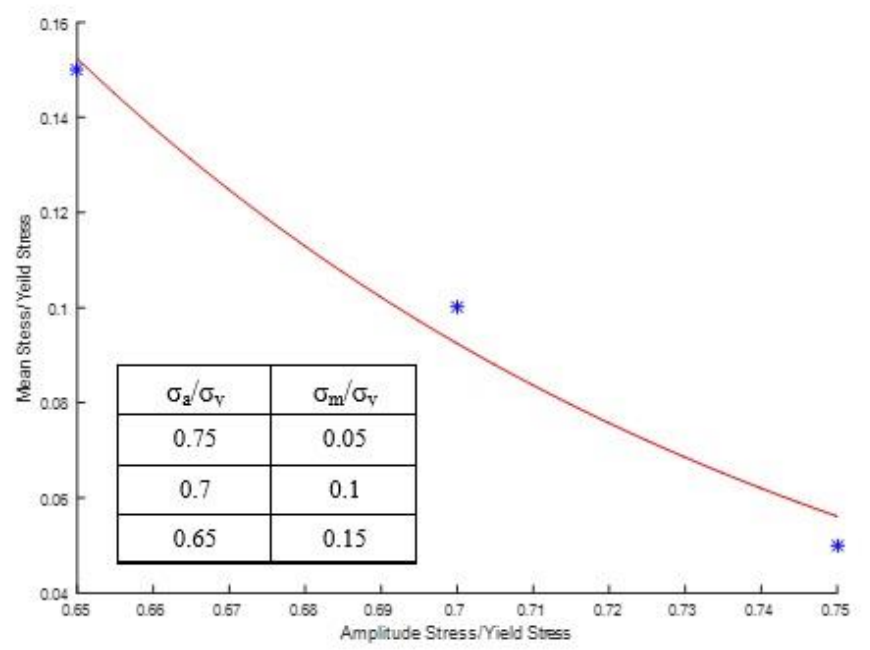

Fig. 4.16: Mean and amplitude stress relation for interstitial free steel at yield stress of 200 MPa. 


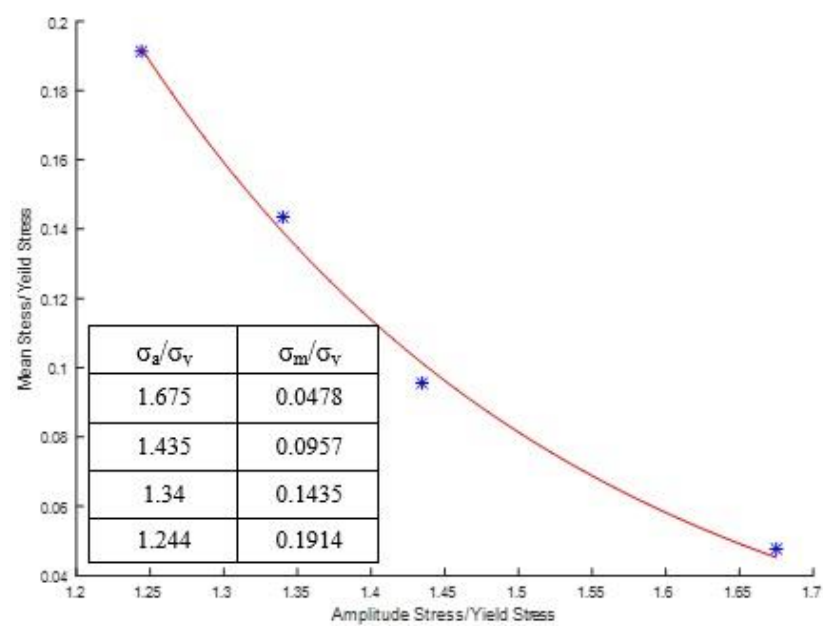

Fig. 4.17: Mean and amplitude stress relation for SS304 steel at yield stress of $209 \mathrm{MPa}$.

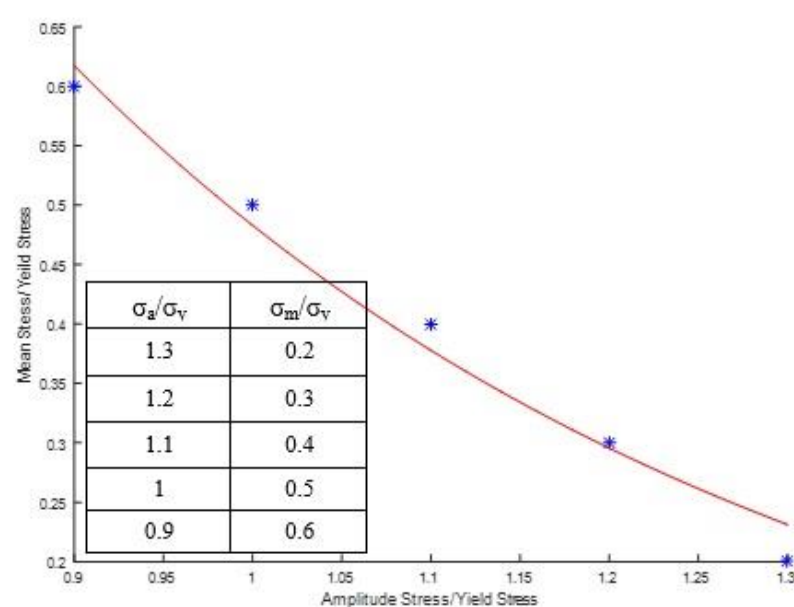

Fig. 4.18: Mean and amplitude stress relation for 42CrMo steel at yield stress of $310 \mathrm{MPa}$.

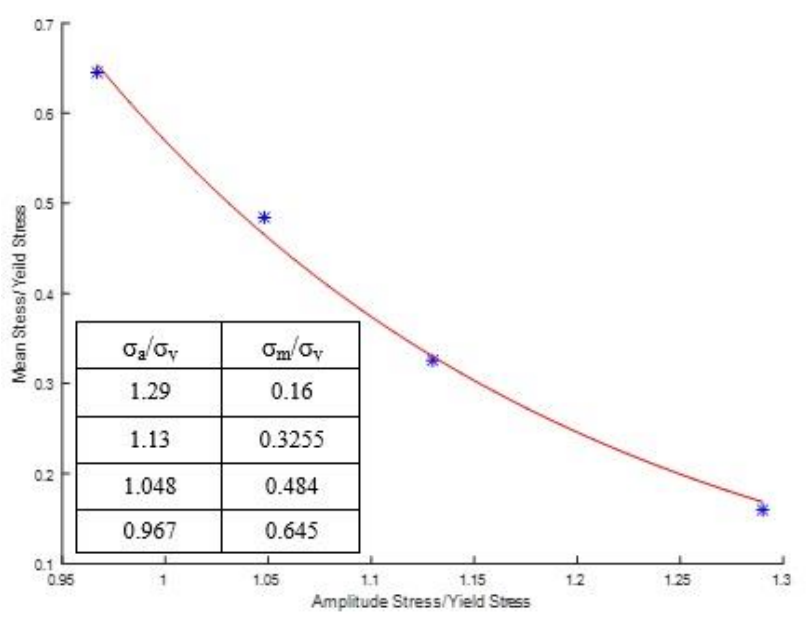

Fig. 4.19: Mean and amplitude stress relation for titanium-stabilized interstitial free steel at yield stress of 144.2 MPa.

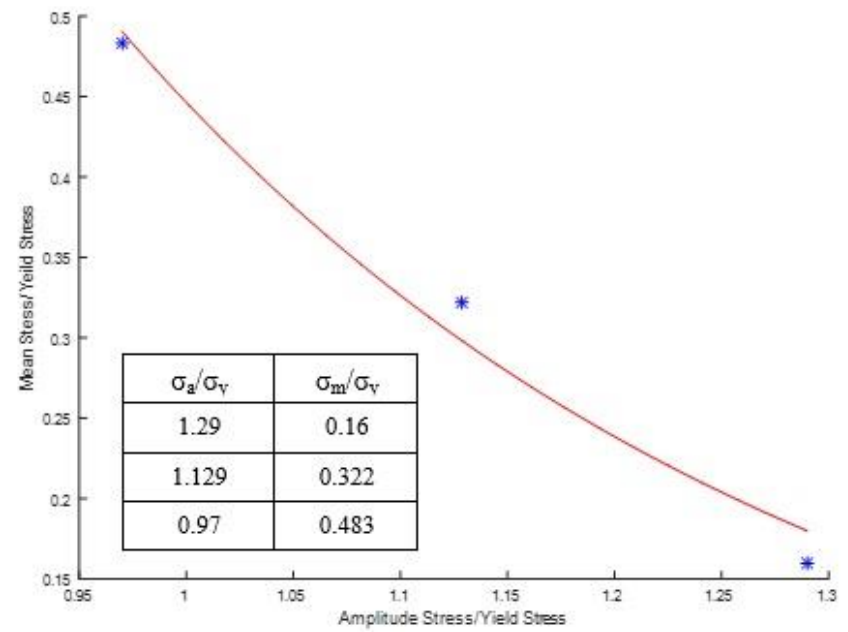

Fig. 4.20: Mean and amplitude stress relation for $42 \mathrm{CrMo}$ steel at yield stress of $310 \mathrm{MPa}$. 


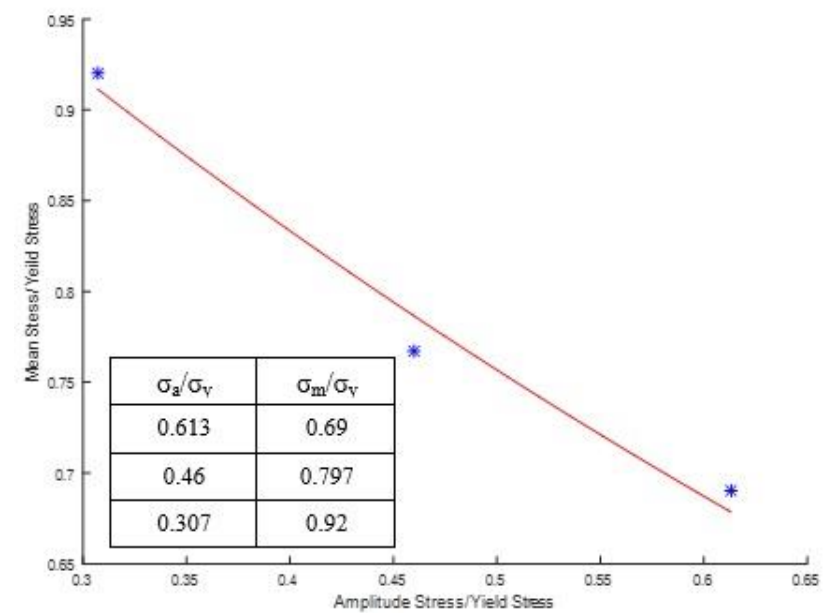

Fig. 4.21: Mean and amplitude stress relation for X13CrMnMoN 18-14-3 high nitrogen steel at yield stress of $830 \mathrm{MPa}$.

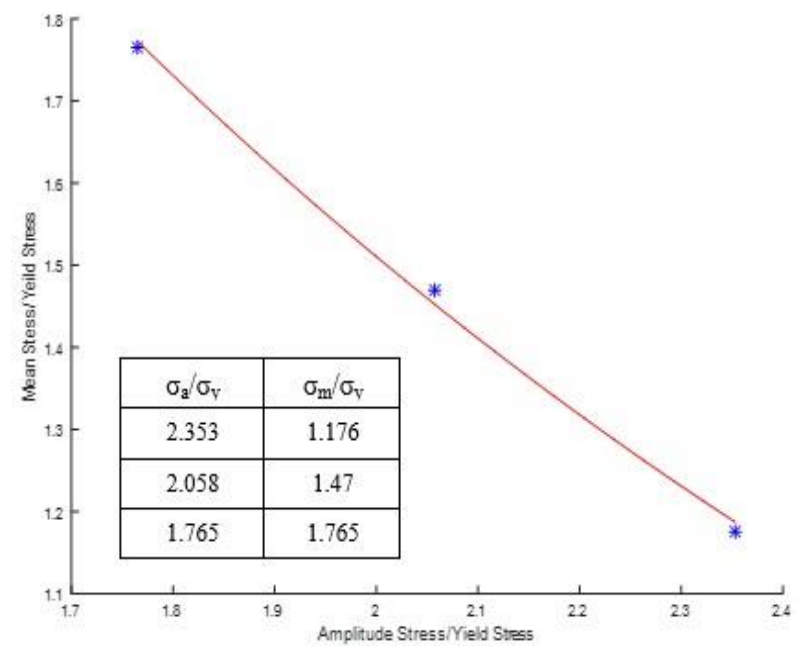

Fig. 4.22: Mean and amplitude stress relation for Z2CND18.12N steel at yield stress of 85 MPa.

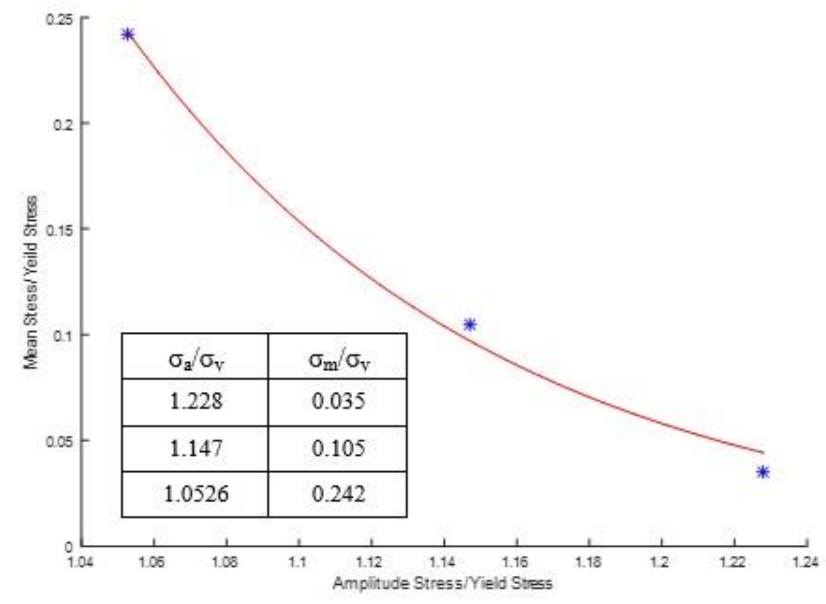

Fig. 4.23: Mean and amplitude stress relation for $316 \mathrm{~L}$ steel at yield stress of $285 \mathrm{MPa}$.

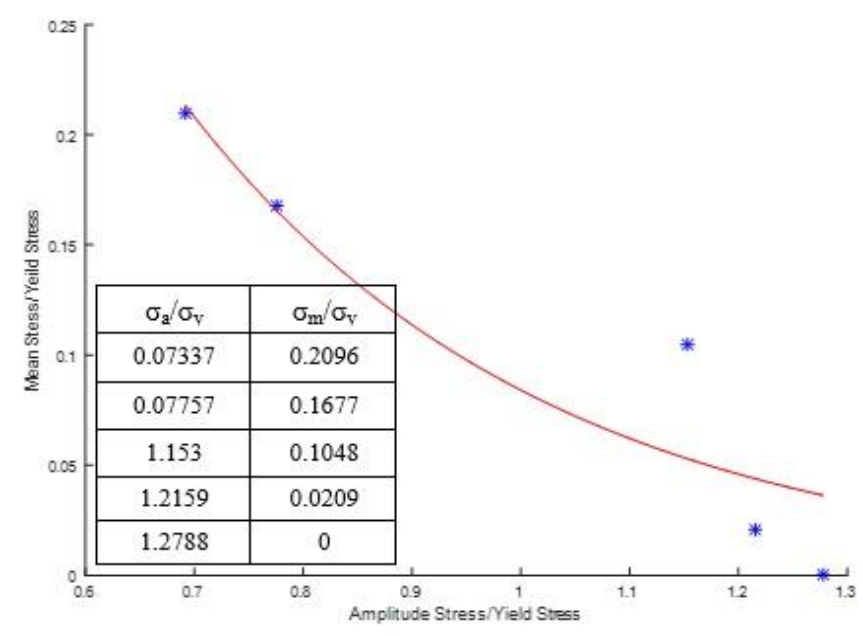

Fig. 4.24: Mean and amplitude stress relation for HC340LA steel at yield stress of 477 MPa. 


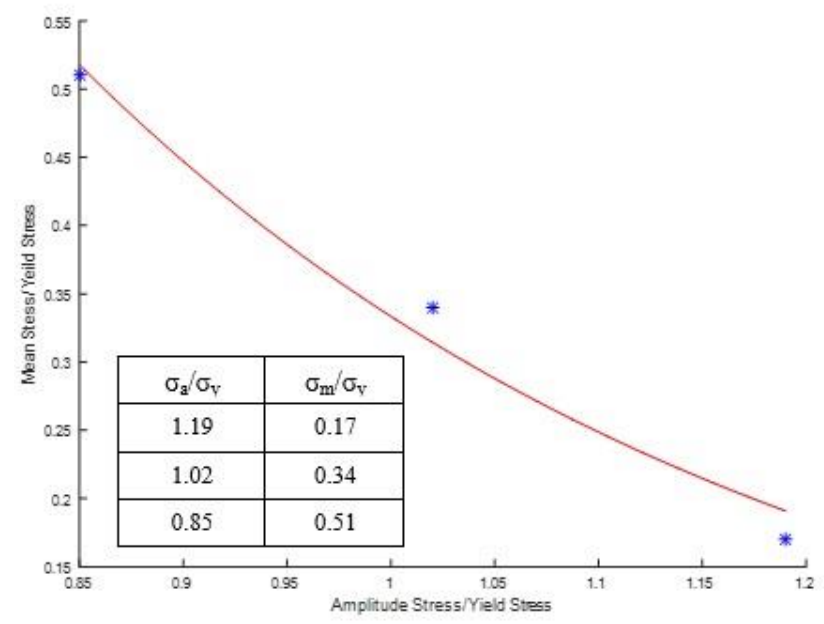

Fig. 4.25: Mean and amplitude stress relation for 304LN steel at yield stress of $353 \mathrm{MPa}$.

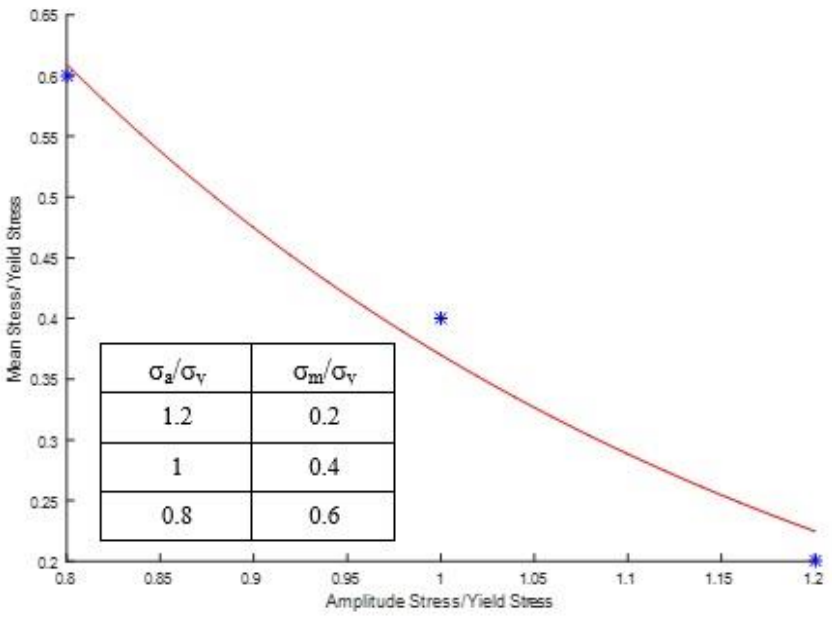

Fig. 4.26: Mean and amplitude stress relation for 20 Steel at yield stress of $250 \mathrm{MPa}$.

The exponential equation of the curve obtained in Fig. 4.15 to 4.26 are in the form of

$F(x)=C \cdot e^{k x}$

where $C$ and $k$ are Constants.

Table 4.2 shows all the constants and real constants value of different material in the Fig. 4.15 4.26 mean and amplitude stress relation graphs.

Table 4.2: Values of the exponential equation constants in mean and amplitude stress relation graphs for different steel materials.

\begin{tabular}{|c|c|c|}
\hline \multirow{2}{*}{ Material } & \multicolumn{2}{|c|}{$F(x)=C . e^{k x}$} \\
\hline & Constant $C$ & Constant $k$ \\
\hline 16MnR Steel & 56799 & -12.63 \\
\hline Interstitial Free Steel & 198.7 & -10.99 \\
\hline SS304 & 10.734 & -3.245 \\
\hline
\end{tabular}




\begin{tabular}{|c|c|c|}
\hline \multirow{2}{*}{ Material } & \multicolumn{2}{|c|}{$F(x)=C . e^{k x}$} \\
\cline { 2 - 3 } & Constant $C$ & Real Constant $k$ \\
\hline 42CrMo Steel & 45.658 & -4.375 \\
\hline $\begin{array}{c}\text { Titanium-Stabilized Free } \\
\text { Steel }\end{array}$ & 7.3311 & -2.708 \\
\hline $\begin{array}{c}\text { 42CrMo Steel Alloy } \\
\text { N13CrMnMoN18-14-3 High }\end{array}$ & 14.458 & -3.455 \\
\hline $\begin{array}{c}\text { Z2CND18-12N Steel } \\
\text { SS316L }\end{array}$ & 1.2123 & -0.94 \\
\hline HC340LA Steel Alloy & 6.0109 & -0.691 \\
\hline 30LN Stainless Steel & 26513 & -10.98 \\
\hline 20 Steel & 2.1917 & -3.287 \\
\hline
\end{tabular}

\subsection{Three dimensional ratcheting surface zone}

Ratcheting three-dimensional surface zone is formulated by combining the solutions of ratcheting strain rate with constant mean stress and varying stress amplitude and also with constant stress amplitude and varying mean stress of different steel alloys from Fig. 4.27-4.37. The mathematical equation used to generate this three-dimensional surface is as follows

$\alpha=\left(m_{1} . \sigma_{m}+m_{2} . \sigma_{a}+c_{1}+c_{2}\right) / 2$

where $\alpha=$ ratcheting strain rate, $\sigma_{m}=$ mean stress, $\sigma_{a}=$ stress amplitude, $m_{l}$ and $m_{2}$ are slope and $c_{1}$ and $c_{2}$ are y intercepts of the linear equation at constant mean stress and constant stress amplitude condition. 
The result shows an irregularly inclined surface. Therefore, we can find the respective for different mean and amplitude stress graphically.

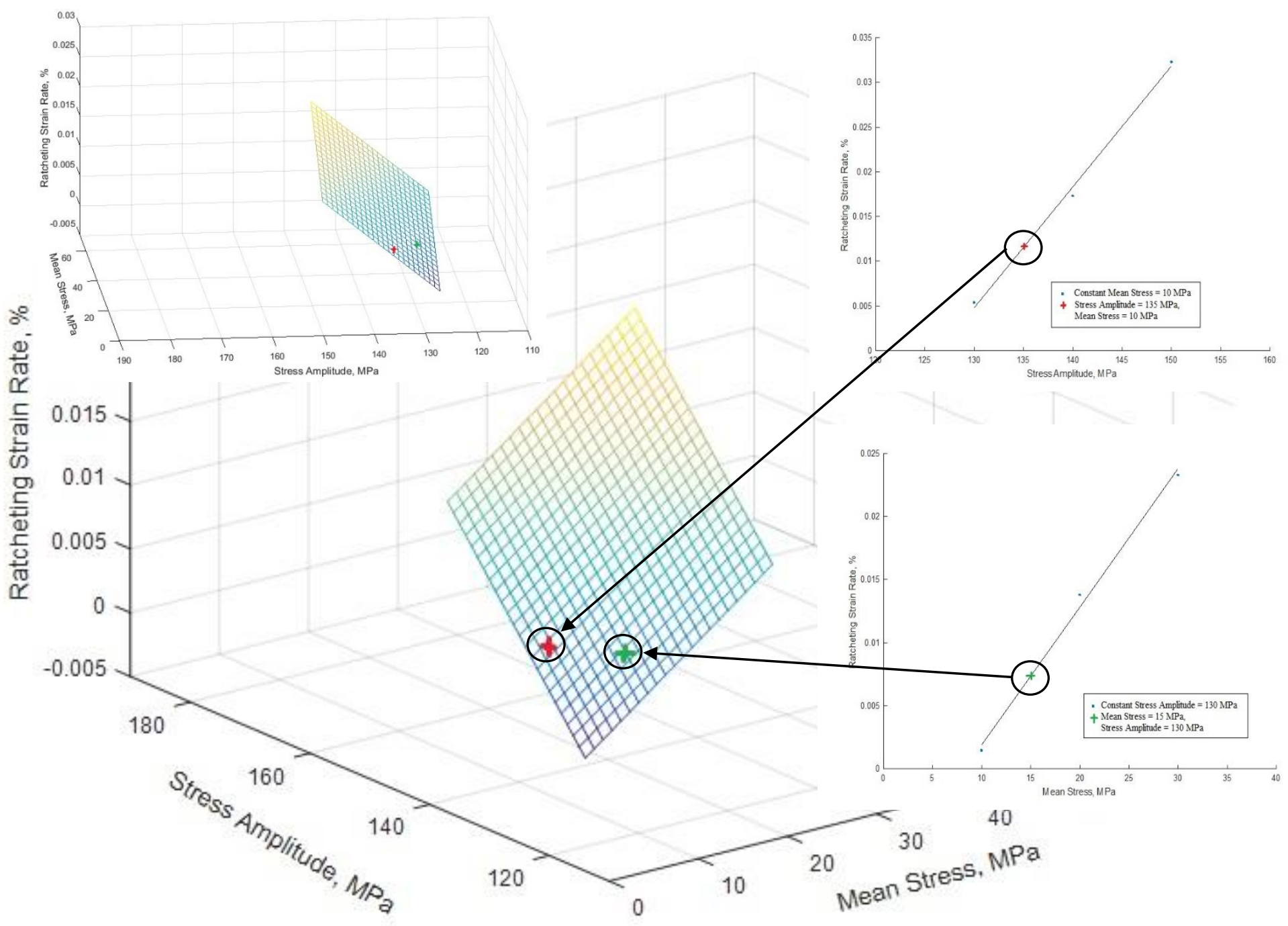

Fig. 4.27: Three dimensional ratcheting surface zone for applied stress amplitude and mean stress for interstitial free steel. 


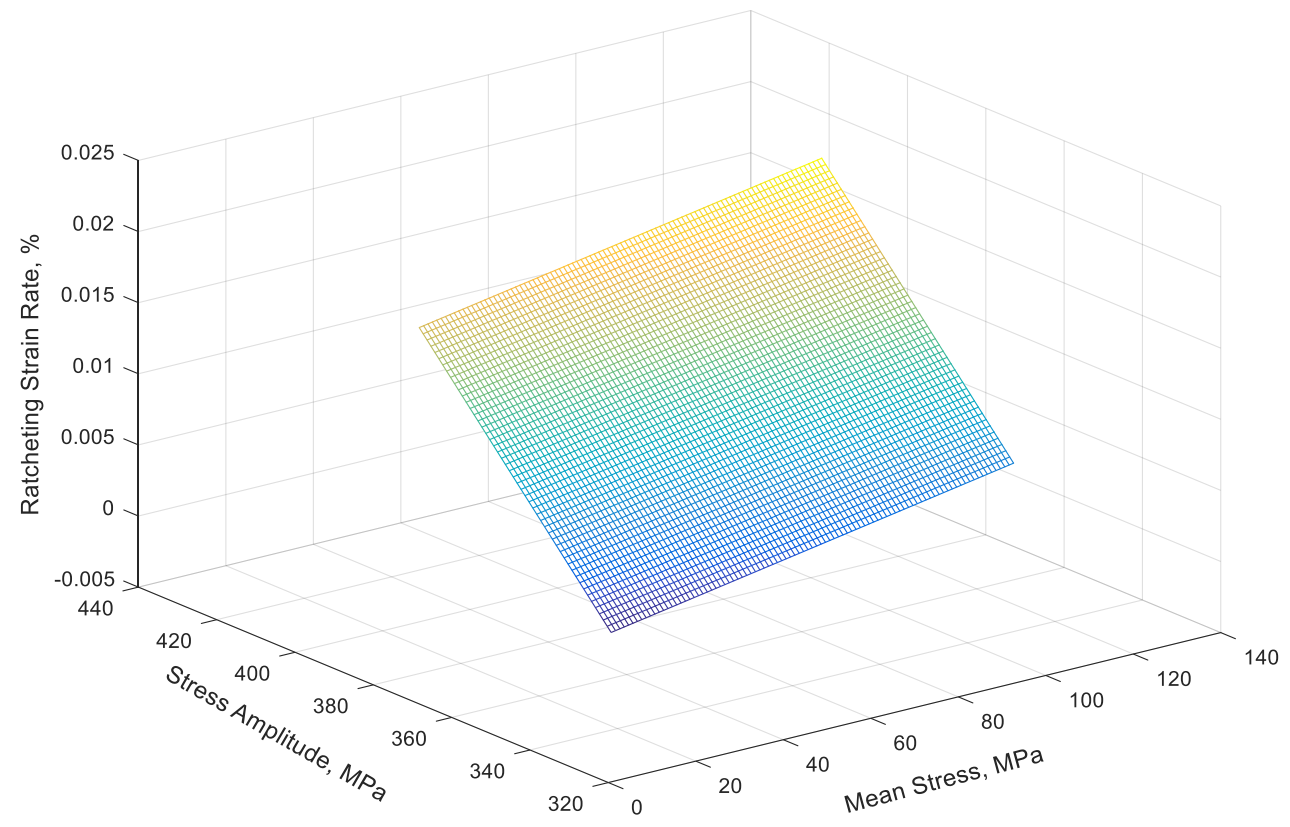

Fig. 4.28: Three dimensional ratcheting surface zone for applied stress amplitude and mean stress for $16 \mathrm{MnR}$ steel.

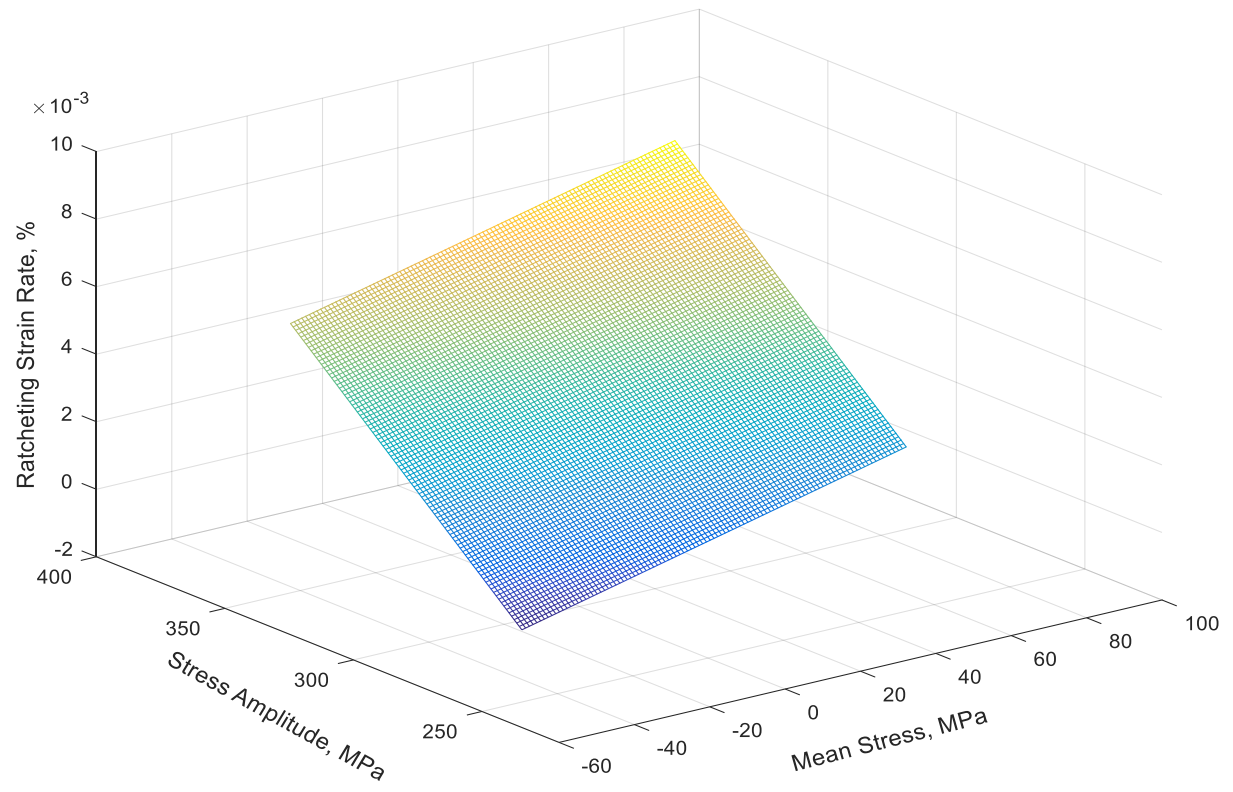

Fig. 4.29: Three dimensional ratcheting surface zone for applied stress amplitude and mean stress for SS304 stainless steel. 


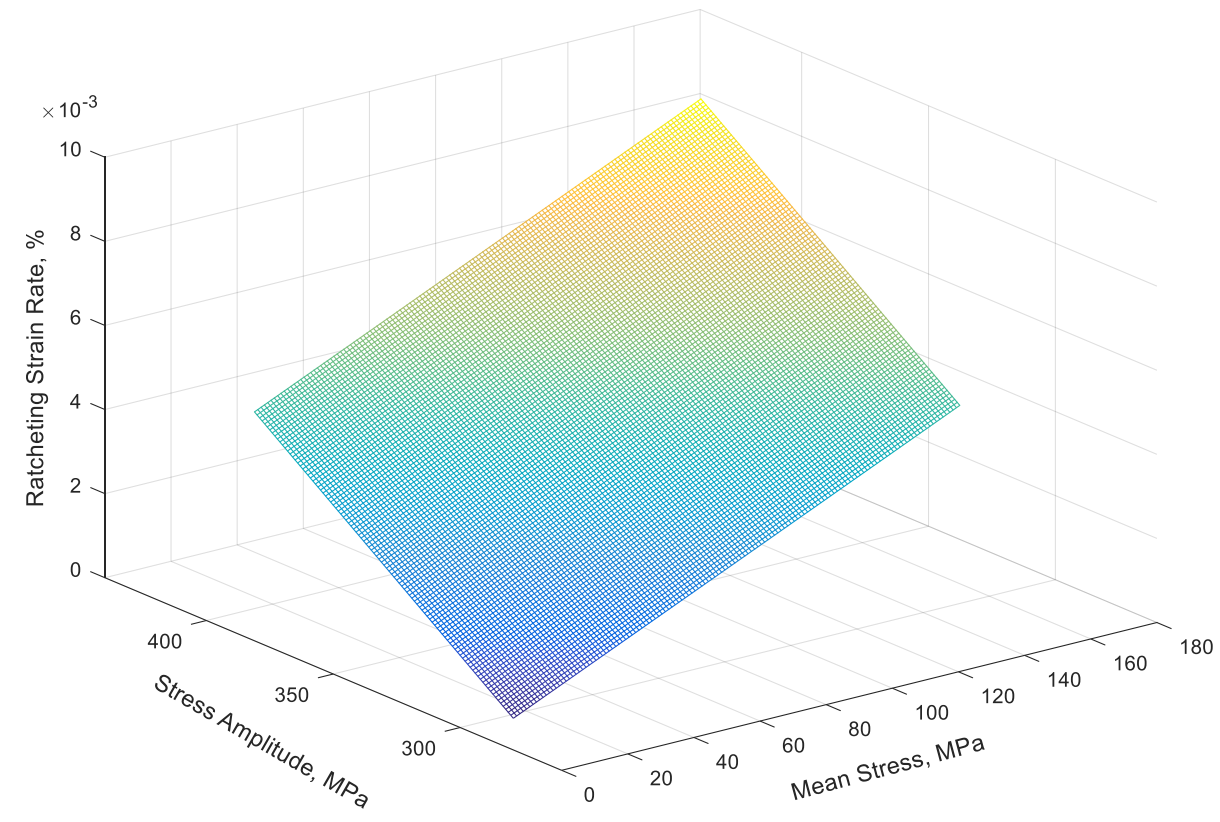

Fig. 4.30: Three dimensional ratcheting surface zone for applied stress amplitude and mean stress for 42CrMo steel.

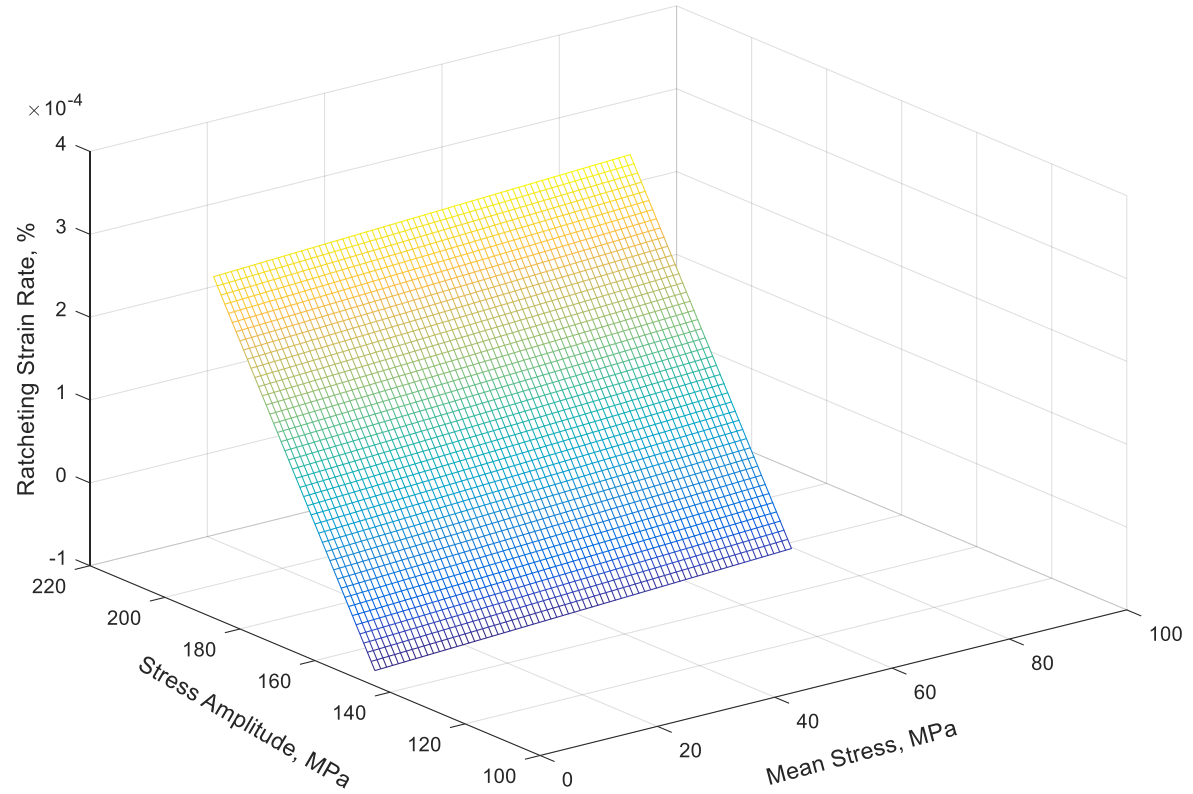

Fig. 4.31: Three dimensional ratcheting surface zone for applied stress amplitude and mean stress for titanium-stabilized free steel. 


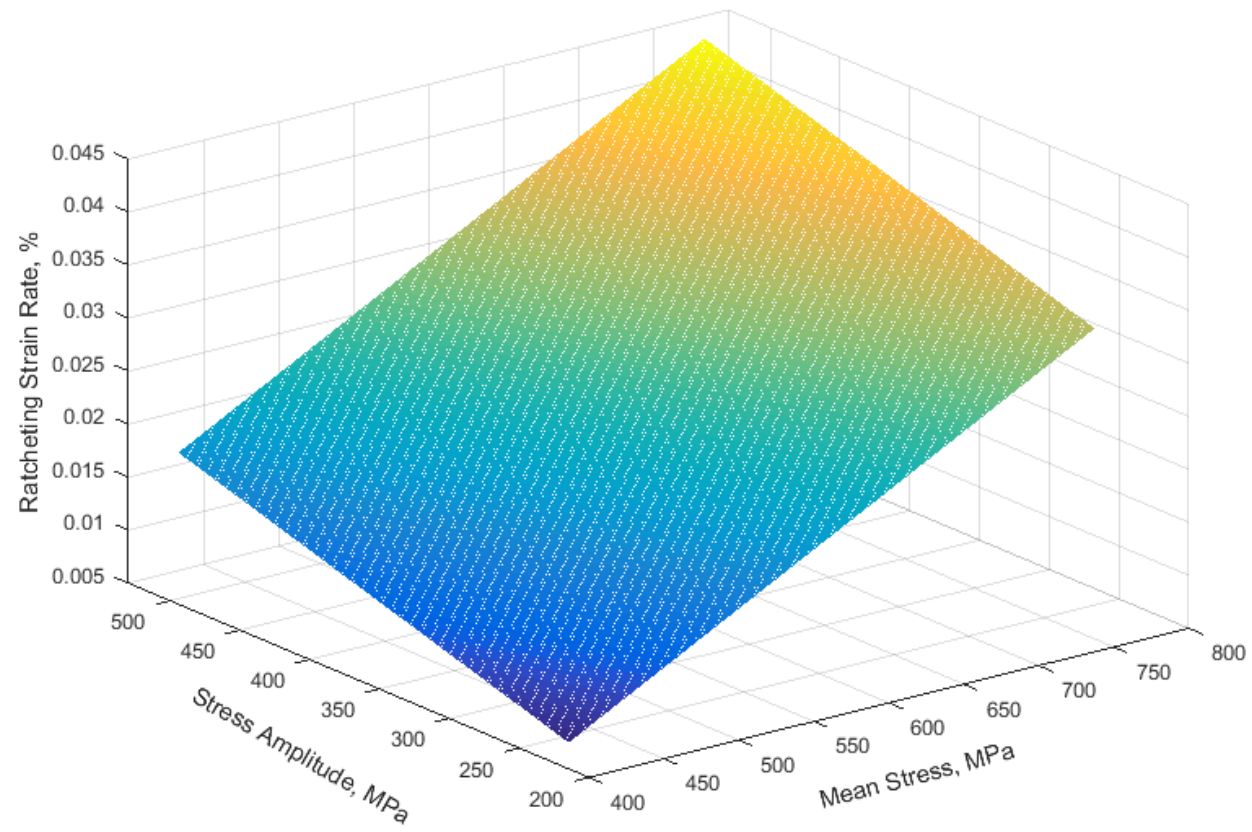

Fig. 4.32: Three dimensional ratcheting surface zone for applied stress amplitude and mean stress for X13CrMnMoN18-14-3 high nitrogen steel.

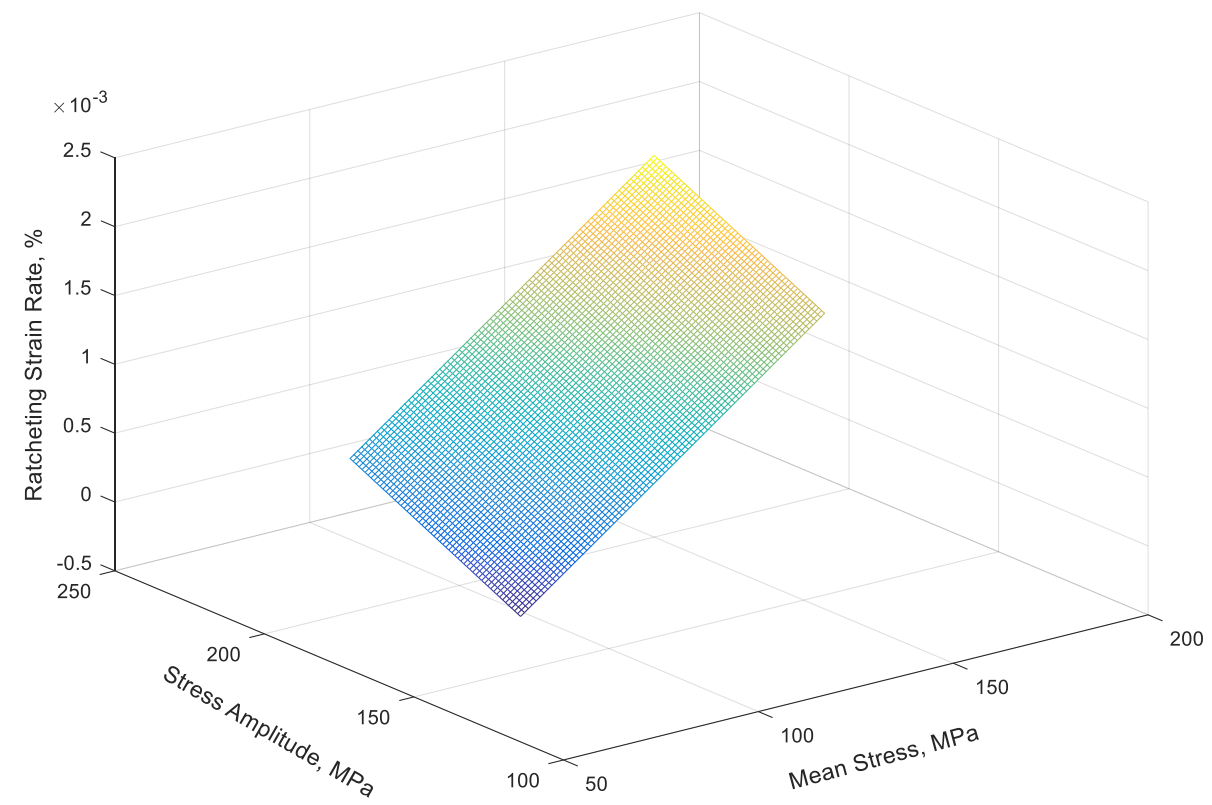

Fig. 4.33: Three dimensional ratcheting surface zone for applied stress amplitude and mean stress for Z2CND18-12N steel. 


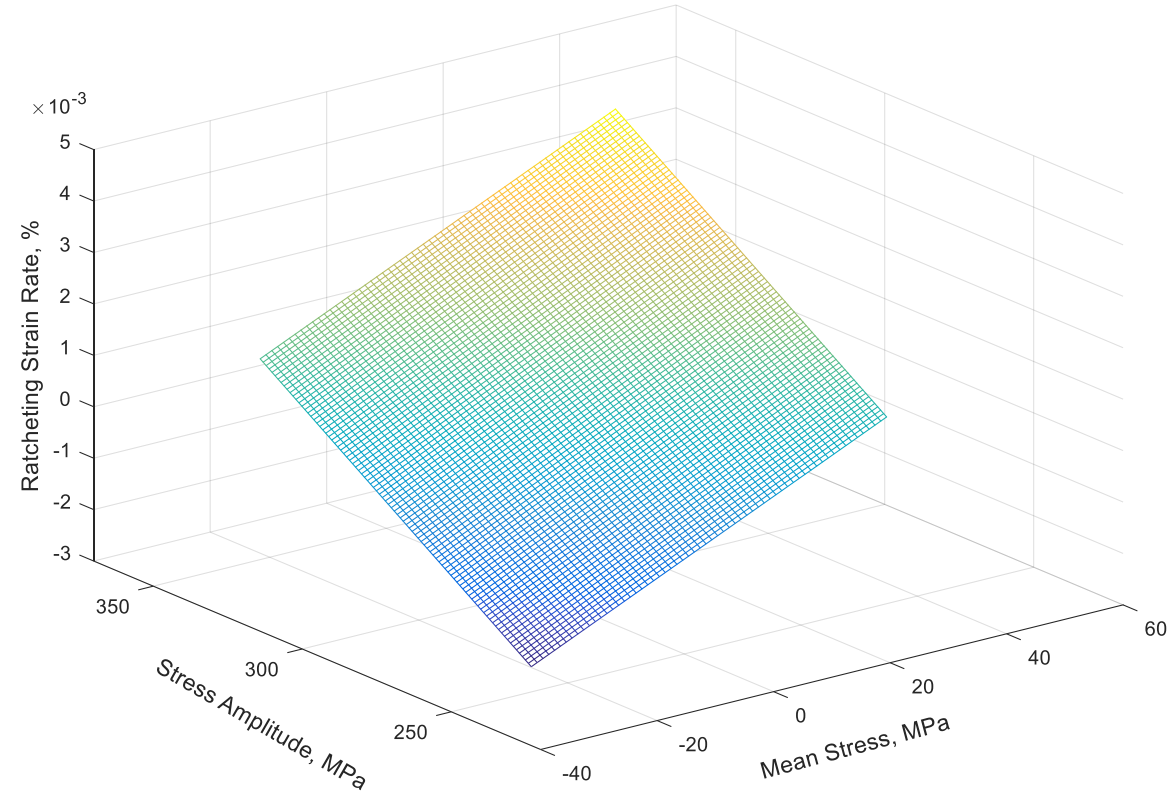

Fig. 4.34: Three dimensional ratcheting surface zone for applied stress amplitude and mean stress for SS316L steel.

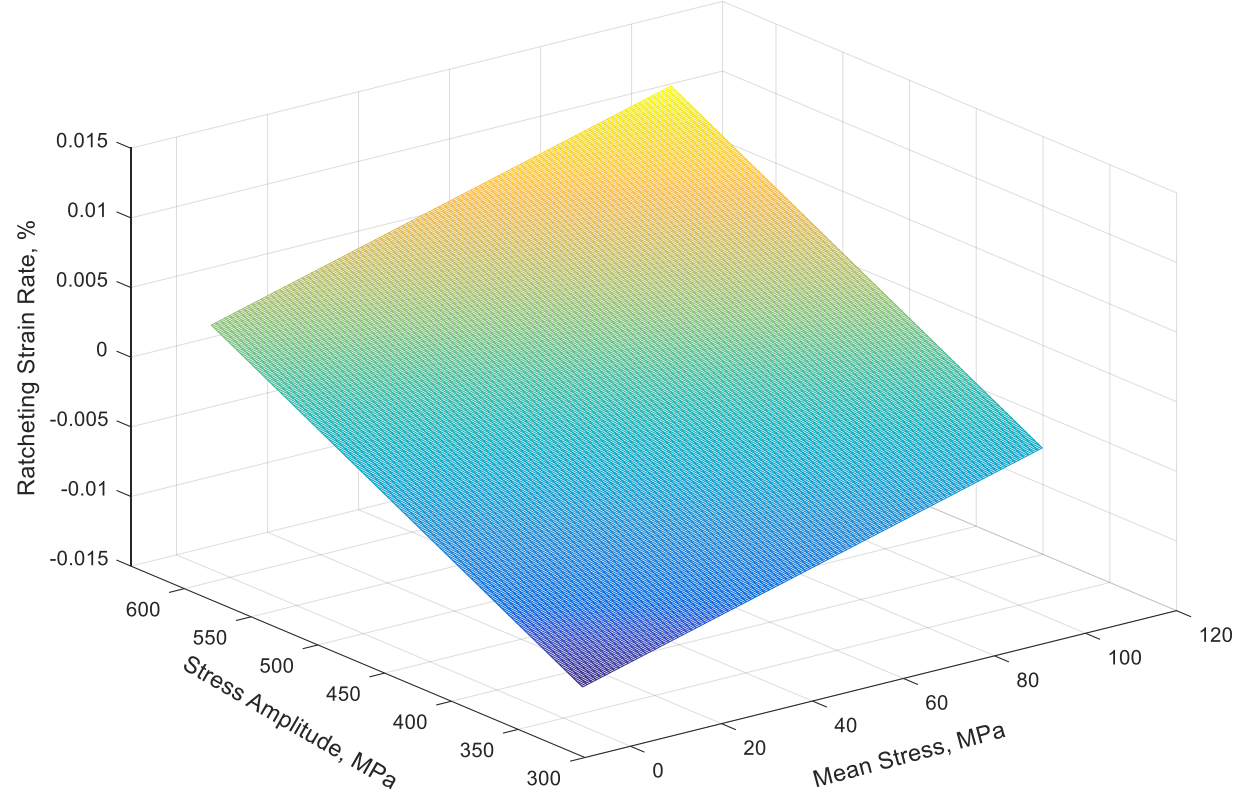

Fig. 4.35: Three dimensional ratcheting surface zone for applied stress amplitude and mean stress for HC340LA steel alloy. 


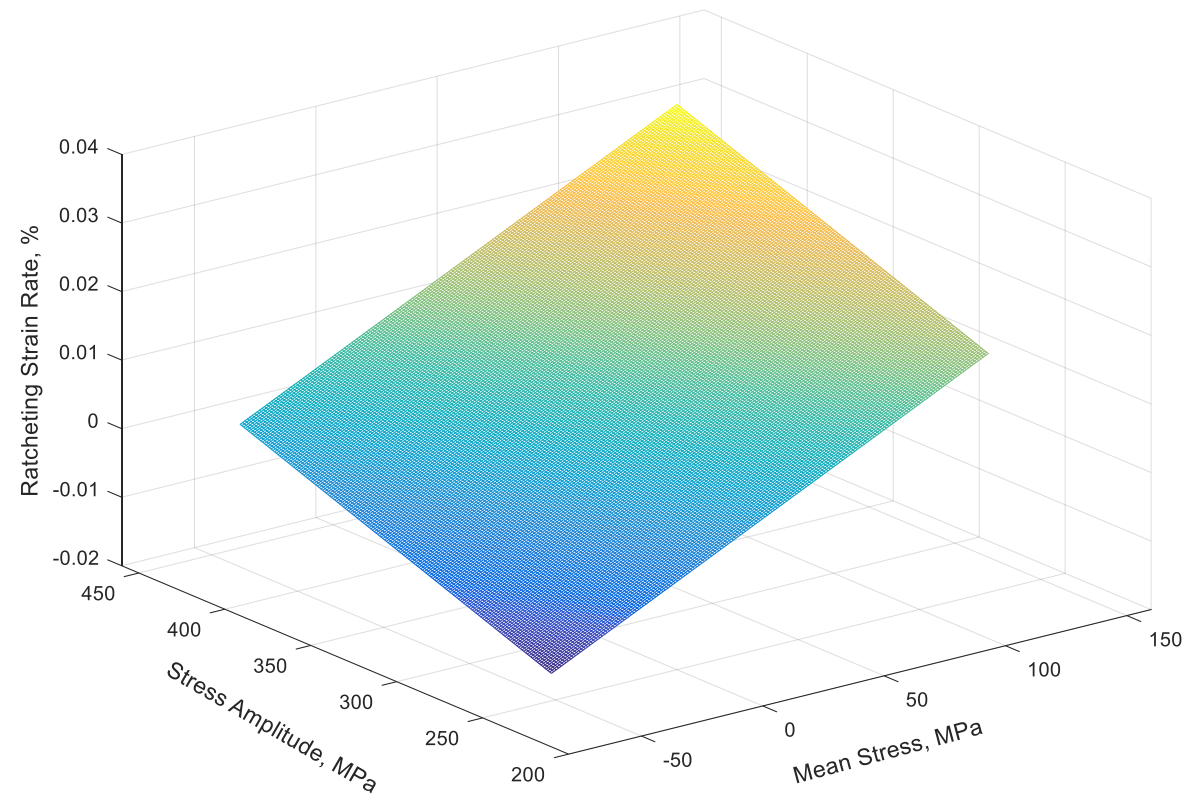

Fig. 4.36: Three dimensional ratcheting surface zone for applied stress amplitude and mean stress for 30LN stainless steel.

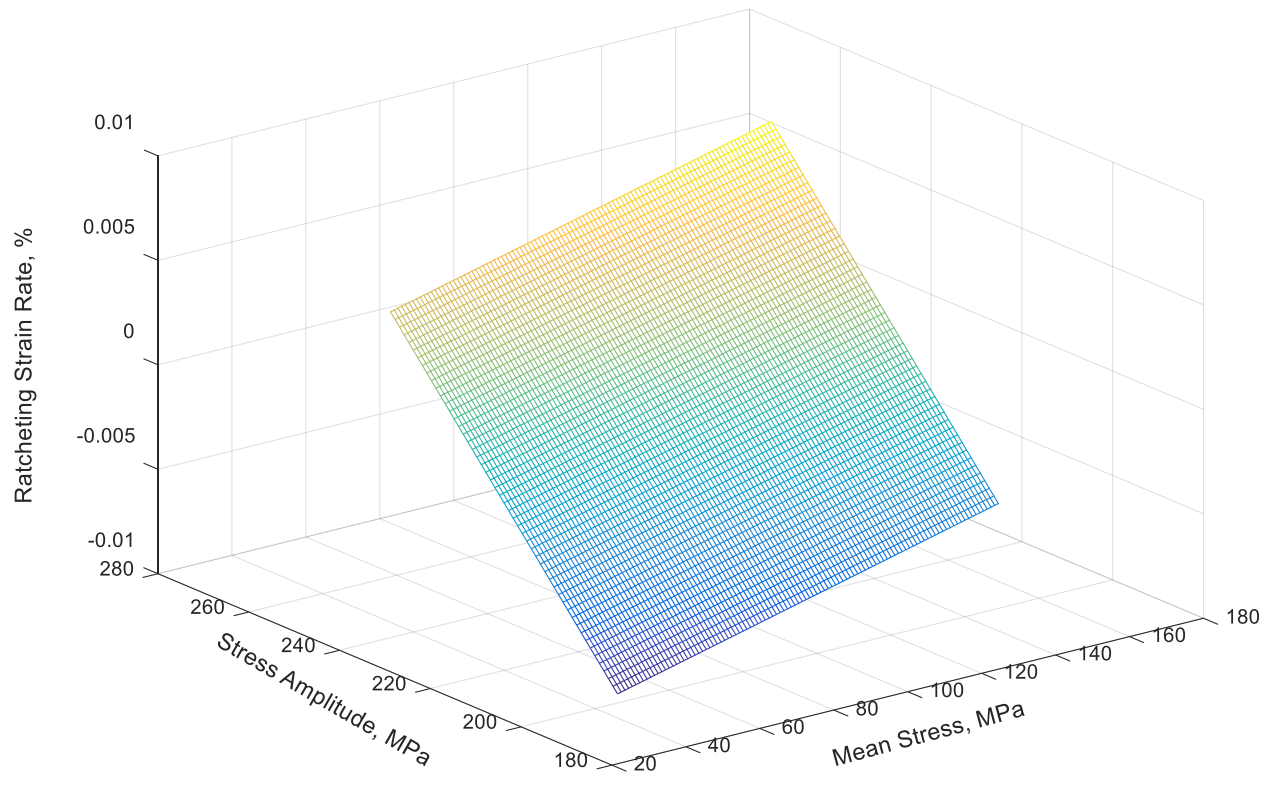

Fig. 4.37: Three dimensional ratcheting surface zone for applied stress amplitude and mean stress for 20 steel. 


\subsection{Overview}

From Fig. $4.27-4.37$ it can be shown that the ratcheting strain of various steel alloys can be found for different sets of applied mean and amplitude stress. The three-dimensional surface zone is constructed with certain boundary limits of maximum mean and amplitude stresses applied in the experiment. The boundaries can be increased by extending the trend line without changing the slopes and intercepts. 


\section{CHAPTER 5}

\section{Conclusion}

The accumulation of ratcheting strain in different steels due to uniaxial loading is found to increase if the magnitude of mean stress increases with constant stress amplitude condition. The ratcheting strain increases with an increase in the magnitude of stress amplitude with constant mean stress state. Cyclic damage in the material increases with an increase in strain accumulation that is illustrated by the hysteresis loop shifting towards the large plastic strain amplitude; due to this ratcheting phenomenon dislocation density in samples increases.

The process of ratcheting can be evaluated in three stages, in stage I ratcheting strain rate decreases with increase in the loading cycles. In stage II ratcheting strain rate reaches a constant with further increase in cycles and during this stage only ratcheting strain keeps on growing at a steady rate. In the final stage, ratcheting strain rate increases drastically until the failure occurs. Hence from Table 2.1 we can conclude that ratcheting can be arrested and cannot be increased further if the material is loaded under zero ratcheting strain rate condition with specified mean stress and stress amplitude.

The three dimensional ratcheting surface is formulated for different steel materials to study the ratcheting behavior of those materials under various combinations of mean and amplitude stresses. These graphs are expressed with the help of experimental results of certain sets of mean and stress amplitude conditions. Multiple sets of stress combinations and their corresponding ratcheting rate can be obtained with some limited sets of experimental results. As a consequence, experimentation cost and time can be saved. 


\section{REFERENCES}

[1] C. Li, G. Chen, X. Chen and W. Zhang. Ratcheting strain and stimulation of 16MnR steel under uniaxial cyclic loading. Computational material science 57 (2012) 43-47.

[2] K. Dutta and K.K. Ray. Ratcheting Strain in interstitial free steel. Materials science and engineering A575 (2013) 127-135.

[3] G. Kang, Y. Liu and Z. Li. Experimental study on ratcheting-fatigue interaction of SS304 stainless steel in uniaxial cyclic loading. Material science and engineering A 435-436 (2006) 396-404.

[4] G. Kang and Y. lie. Uniaxial ratcheting and low-cycle fatigue failure of the steel with cyclic stabilizing or softening feature. Material science and engineering A 472 (2008) 258-268.

[5] P.S. De, P.C. Chakraborti, B. Bhattacharya, M. Shome and D.Bhattacharjee. Ratcheting behavior of titanium-stabilized interstitial free steel. Metallurgical and materials transactions 44(5) (2013) 2106-2120.

[6] G.R. Ahmadzadeh and A. Varvani-Farahani. Ratcheting assessment of steel alloys under uniaxial loading: a parametric model versus hardening rule of bower. Fatigue and fracture engineering materials and structures 36(4) (2013) 281-292.

[7] K. Dutta, L. Sahu and A. K. Mishra. Ratcheting behavior of non-conventional stainless steel and associated microstructural variations. JMEPEG 23(11) (2014) 4122-4129.

[8] G.R. Ahmadzadeh and A. Varvani-Farahani. Triphasic ratcheting strain prediction of material over stress cycles. Fatigue and fracture of engineering material and structures 35(10) (2012) 929-935.

[9] G. Chen, X. Chen and C. Niu. Uniaxial ratcheting behavior of $63 \mathrm{Sn} 37 \mathrm{~Pb}$ solder with loading histories and stress rates. Material science and engineering A 421(1) (2006) 238244.

[10] G. Chen, S. Shan, X. Chen and H. Yuan. Ratcheting and fatigue properties of the highnitrogen steel X13CrMnMoN18-14-3 under cyclic loading. Computational material science 46(3) (2009) 572-578.

[11] D. Yu, G. Chen, W. Yu, D. Li and X. Chen. Visco-plastic constitutive modeling on ohnowang kinematic hardening rule for uniaxial ratcheting behavior of Z2CND18.12N steel. International journal of plasticity 28(1) (2012) 88-101. 
[12] G.R. Ahmadzadeh and A.Varvani-Farahani. Ratcheting assessment of materials based on the modified Armstrong-frederick hardening rule at various uniaxial stress levels. Fatigue and fracture of engineering materials and structures 36(12) (2013) 1232-1245.

[13] V.D. Palma, A. Tomasella, F. Frendo, C.M. Sonsino and T. Melz. Experimental analysis of the ratcheting behavior of linear flow split flanges of HC340LA. International journal of fatigue 64 (2014) 121-130.

[14] G. Kang, Y. Liu and Q. Gao. Uniaxial ratchetting-fatigue interaction of tempered 42CrMo steel and its failure model. Advanced materials research 33-37 (2008) 115-120.

[15] P.P. Dey, N. Khutia, S. Sivaprasad and S. Tarafder. Development of new cyclic plasticity model for 304LN stainless steel through simulation and experimental investigation. Mechanics of materials 78 (2014) 85-101.

[16] Y. Liu, Y. Dong, G. Kang, H. Wang, X. Cheng. Experimental study on uniaxial ratcheting of 20 steel with high number of cycles at room temperature. Acta metallurgica sinica 45(7) (2009) 826-829.

[17] G.R. Ahmadzadeh, S.M. Hamidinejad and A. Varvani-Farahani. Ratcheting prediction of 1070 and $16 \mathrm{MnR}$ steel alloys under uniaxial asymmetric stress cycles by means of OhnoWang and Ahmadzadeh-Varvani kinematic hardening rules. Journal of pressure vessel technology 137(3) (2015) 031001-1. 


\section{APPENDIX A}

\section{Mechanical Properties of materials}

Table A.1 Mechanical properties of different steel alloys

\begin{tabular}{|c|c|c|c|c|c|}
\hline Material & $\begin{array}{c}\text { Young's } \\
\text { Modulus } \\
\text { (MPa) }\end{array}$ & $\begin{array}{c}\text { Yield } \\
\text { Stress } \\
(\mathrm{MPa})\end{array}$ & $\begin{array}{c}\text { Ultimate } \\
\text { Stress (MPa) }\end{array}$ & $\begin{array}{c}\text { Elongation } \\
(\%)\end{array}$ & $\begin{array}{c}\text { Poisson's } \\
\text { Ratio }\end{array}$ \\
\hline 16MnR Steel & $2.1 \mathrm{E}^{5}$ & 378 & 582 & 27 & 0.28 \\
\hline Interstitial Free Steel & $1.62 \mathrm{E}^{5}$ & 200 & 330 & 36 & 0.27 \\
\hline 42CrMo Steel & $1.905 \mathrm{E}^{5}$ & 310 & 670 & 15 & 0.28 \\
\hline $\begin{array}{c}\text { Titanium-Stabilized } \\
\text { Interstitial Free Steel }\end{array}$ & $1.34 \mathrm{E}^{5}$ & 144.2 & 276.16 & 26.98 & 0.27 \\
\hline SS304 & $1.9 \mathrm{E}^{5}$ & 209 & 475 & 60 & 0.29 \\
\hline X12CrMnNiN17-7-5 Steel & $1.7 \mathrm{E}^{5}$ & 154 & 231 & 45 & 0.27 \\
\hline 20CS Steel & $2.03 \mathrm{E}^{5}$ & 350 & 441 & 28 & 0.3 \\
\hline X13CrMnMoN18-14-3 & $2 \mathrm{E}^{5}$ & 830 & 1150 & 40 & 0.29 \\
\hline High Nitrogen Steel & $1.95 \mathrm{E}^{5}$ & 85 & 165 & 38 & 0.3 \\
\hline Z2CND18.12N Steel & $1.9 \mathrm{E}^{5}$ & 285 & 480 & 40 & 0.265 \\
\hline 316L Steel & $1.76 \mathrm{E}^{5}$ & 477 & 488 & 18 & 0.28 \\
\hline HC340LA Steel & $2 \mathrm{E}^{5}$ & 353 & 671 & 52.8 & 0.29 \\
\hline 304LN Stainless Steel & $1.85 \mathrm{E}^{5}$ & 250 & 380 & 45 & 0.28 \\
\hline
\end{tabular}




\section{APPENDIX B}

\section{Ratcheting strain rate of materials}

Table A.2 Experimental values of ratcheting strain rate in different steel alloys

\begin{tabular}{|c|c|c|c|c|}
\hline Material & $\begin{array}{c}\text { Mean Stress, } \\
\text { MPa }\end{array}$ & $\begin{array}{c}\text { Stress Amplitude, } \\
\text { MPa }\end{array}$ & $\begin{array}{c}\text { Ratcheting Strain } \\
\text { Rate, } \%\end{array}$ & Figures \\
\hline \multirow{5}{*}{$16 \mathrm{MnR}$ steel } & 60 & \multirow{3}{*}{360} & 0.00355 & \multirow{5}{*}{4.2} \\
\hline & 100 & & 0.00763 & \\
\hline & 120 & & 0.0101 & \\
\hline & \multirow{2}{*}{100} & 360 & 0.00628 & \\
\hline & & 380 & 0.0192 & \\
\hline \multirow{12}{*}{ interstitial free steel } & 10 & \multirow{3}{*}{130} & 0.00144 & \multirow{12}{*}{4.3} \\
\hline & 20 & & 0.0138 & \\
\hline & 30 & & 0.0233 & \\
\hline & 10 & \multirow{3}{*}{140} & 0.0208 & \\
\hline & 20 & & 0.0265 & \\
\hline & 30 & & 0.0289 & \\
\hline & 10 & \multirow{3}{*}{150} & 0.0331 & \\
\hline & 20 & & 0.0337 & \\
\hline & 30 & & 0.035 & \\
\hline & \multirow{3}{*}{10} & 130 & 0.00538 & \\
\hline & & 140 & 0.0173 & \\
\hline & & 150 & 0.0323 & \\
\hline \multirow{10}{*}{$\begin{array}{c}\text { SS304 stainless } \\
\text { steel }\end{array}$} & 5 & \multirow{6}{*}{300} & 0.00192 & \multirow{10}{*}{4.4} \\
\hline & 10 & & 0.00273 & \\
\hline & 20 & & 0.00348 & \\
\hline & 30 & & 0.00397 & \\
\hline & 40 & & 0.00415 & \\
\hline & 60 & & 0.00529 & \\
\hline & \multirow{4}{*}{10} & 260 & 0.00112 & \\
\hline & & 280 & 0.00181 & \\
\hline & & 300 & 0.00364 & \\
\hline & & 350 & 0.01257 & \\
\hline \multirow{3}{*}{ 42CrMo steel } & 50 & \multirow{3}{*}{350} & 0.00263 & \multirow{3}{*}{4.5} \\
\hline & 100 & & 0.00593 & \\
\hline & 150 & & 0.00975 & \\
\hline
\end{tabular}




\begin{tabular}{|c|c|c|c|c|}
\hline Material & $\begin{array}{c}\text { Mean Stress, } \\
\text { MPa }\end{array}$ & $\begin{array}{c}\text { Stress Amplitude, } \\
\text { MPa }\end{array}$ & $\begin{array}{c}\text { Ratcheting Strain } \\
\text { Rate, } \%\end{array}$ & Figures \\
\hline \multirow{4}{*}{ 42CrMo steel } & \multirow[t]{4}{*}{50} & 300 & 0.000971 & \multirow{4}{*}{4.5} \\
\hline & & 325 & 0.002174 & \\
\hline & & 350 & 0.00308 & \\
\hline & & 400 & 0.01 & \\
\hline \multirow{6}{*}{$\begin{array}{l}\text { titanium-stabilized } \\
\text { steel }\end{array}$} & 43.26 & \multirow[t]{3}{*}{144.2} & 0.00264 & \multirow{6}{*}{4.6} \\
\hline & 57.68 & & 0.00385 & \\
\hline & 72.1 & & 0.00447 & \\
\hline & \multirow[t]{3}{*}{28.84} & 158.62 & 0.00795 & \\
\hline & & 173.04 & 0.04035 & \\
\hline & & 187.48 & 0.06075 & \\
\hline \multirow[t]{4}{*}{1020 steel } & 100 & \multirow[t]{2}{*}{350} & 0.00571 & \multirow{7}{*}{4.7} \\
\hline & 150 & & 0.00763 & \\
\hline & 50 & 320 & 0.0277 & \\
\hline & & 300 & 0.00773 & \\
\hline \multirow{3}{*}{$\begin{array}{c}\text { SA } 333 \text { Gr6C-Mn } \\
\text { steel }\end{array}$} & 40 & \multirow[t]{3}{*}{310} & 0.00389 & \\
\hline & 80 & & 0.0238 & \\
\hline & 120 & & 0.042 & \\
\hline \multirow[t]{3}{*}{ 20CS steel } & \multirow[t]{3}{*}{50} & 275 & 0.00265 & \multirow{3}{*}{4.8} \\
\hline & & 30 & 0.01375 & \\
\hline & & 320 & 0.0586 & \\
\hline \multirow{6}{*}{$\begin{array}{l}\text { X13CrMnMoN18- } \\
\text { 14-3 high nitrogen } \\
\text { steel }\end{array}$} & 573 & \multirow[t]{3}{*}{382} & 0.0123 & \multirow{6}{*}{4.9} \\
\hline & 637 & & 0.0206 & \\
\hline & 764 & & 0.029 & \\
\hline & \multirow[t]{3}{*}{637} & 255 & 0.005143 & \\
\hline & & 382 & 0.02086 & \\
\hline & & 509 & 0.04286 & \\
\hline \multirow{3}{*}{$\begin{array}{c}\text { Z2CND18-12N } \\
\text { steel }\end{array}$} & 100 & 200 & 0.00312 & \multirow{3}{*}{4.10} \\
\hline & 125 & & 0.002 & \\
\hline & 150 & & 0.00344 & \\
\hline
\end{tabular}




\begin{tabular}{|c|c|c|c|c|}
\hline Material & $\begin{array}{c}\text { Mean Stress, } \\
\mathrm{MPa}\end{array}$ & $\begin{array}{c}\text { Stress Amplitude, } \\
\mathrm{MPa}\end{array}$ & $\begin{array}{c}\text { Ratcheting Strain } \\
\text { Rate, } \%\end{array}$ & Figures \\
\hline \multirow{3}{*}{$\begin{array}{c}\text { Z2CND18-12N } \\
\text { steel }\end{array}$} & \multirow{3}{*}{125} & 150 & 0.000233 & \multirow{3}{*}{4.10} \\
\hline & & 175 & 0.000533 & \\
\hline & & 200 & 0.00133 & \\
\hline \multirow{9}{*}{ SS304 Steel } & 5 & \multirow{5}{*}{300} & 0.002242 & \multirow{21}{*}{4.11} \\
\hline & 10 & & 0.002826 & \\
\hline & 20 & & 0.00383 & \\
\hline & 30 & & 0.004587 & \\
\hline & 40 & & 0.004954 & \\
\hline & \multirow{4}{*}{10} & 260 & 0.001095 & \\
\hline & & 280 & 0.001552 & \\
\hline & & 300 & 0.003496 & \\
\hline & & 350 & 0.00991 & \\
\hline \multirow{6}{*}{ 42CrMo Steel } & 50 & \multirow{3}{*}{350} & 0.004286 & \\
\hline & 100 & & 0.006974 & \\
\hline & 150 & & 0.00894 & \\
\hline & \multirow{3}{*}{50} & 325 & 0.002 & \\
\hline & & 350 & 0.00426 & \\
\hline & & 400 & 0.0116 & \\
\hline \multirow{6}{*}{ SS316L Steel } & 10 & \multirow{3}{*}{346} & 0.00394 & \\
\hline & 30 & & 0.005961 & \\
\hline & 69 & & 0.00769 & \\
\hline & \multirow{3}{*}{69} & 300 & 0.001959 & \\
\hline & & 327 & 0.00404 & \\
\hline & & 346 & 0.00842 & \\
\hline \multirow{3}{*}{ HC340LA steel } & 0 & \multirow{3}{*}{350} & 0.00068 & \multirow{3}{*}{4.12} \\
\hline & 30 & & 0.002 & \\
\hline & 50 & & 0.00625 & \\
\hline
\end{tabular}




\begin{tabular}{|c|c|c|c|c|}
\hline Material & $\begin{array}{c}\text { Mean Stress, } \\
\text { MPa }\end{array}$ & $\begin{array}{c}\text { Stress Amplitude, } \\
\text { MPa }\end{array}$ & $\begin{array}{c}\text { Ratcheting Strain } \\
\text { Rate, } \%\end{array}$ & Figures \\
\hline \multirow{10}{*}{ HC340LA steel } & \multirow{3}{*}{30} & 330 & 0.000182 & \multirow{3}{*}{4.12} \\
\hline & & 350 & 0.00258 & \\
\hline & & 370 & 0.007286 & \\
\hline & 20 & \multirow{4}{*}{600} & 0.002783 & \multirow{7}{*}{4.13} \\
\hline & 50 & & 0.00662 & \\
\hline & 80 & & 0.01257 & \\
\hline & 100 & & 0.0205 & \\
\hline & \multirow{3}{*}{100} & 550 & 0.000938 & \\
\hline & & 580 & 0.0046 & \\
\hline & & 610 & 0.0113 & \\
\hline \multirow{8}{*}{$\begin{array}{c}\text { 304LN Stainless } \\
\text { steel }\end{array}$} & -60 & \multirow{5}{*}{420} & -0.0361 & \multirow{15}{*}{4.14} \\
\hline & 0 & & 0.00147 & \\
\hline & 60 & & 0.0218 & \\
\hline & 120 & & 0.0341 & \\
\hline & 180 & & 0.047 & \\
\hline & \multirow{3}{*}{120} & 300 & 0.0133 & \\
\hline & & 360 & 0.022 & \\
\hline & & 420 & 0.03611 & \\
\hline \multirow{7}{*}{20 Steel } & 50 & \multirow{3}{*}{250} & 0.0011 & \\
\hline & 100 & & 0.0033 & \\
\hline & 150 & & 0.01 & \\
\hline & \multirow{4}{*}{100} & 225 & 0.00083 & \\
\hline & & 250 & 0.00267 & \\
\hline & & 275 & 0.0144 & \\
\hline & & 300 & 0.0426 & \\
\hline
\end{tabular}




\section{APPENDIX C \\ MATLAB code to generate plots for ratcheting strain rate vs. mean stress}

Example of MATLAB code used to generate plots and linear fit line for ratcheting strain rate vs. mean stress at constant stress amplitude and ratcheting strain rate vs. stress amplitude at constant mean stress.

clear all;

clc;

format long

$\mathrm{x}=[10 ; 20 ; 30]$;

$\mathrm{y}=[0.00144 ; 0.0138 ; 0.0233]$;

$\mathrm{x} 1=[10 ; 20 ; 30]$;

$\mathrm{y} 1=[0.01208 ; 0.02165 ; 0.0289]$;

$\mathrm{x} 2=[10 ; 20 ; 30]$;

y2 $=[0.02331 ; 0.0317 ; 0.035]$;

hold on

$\operatorname{plot}\left(\mathrm{x}, \mathrm{y},{ }^{\prime}{ }^{\prime}\right)$

plot(x,y1,'.')

$\operatorname{plot}\left(\mathrm{x}, \mathrm{y} 2,{ }^{\prime}+'\right)$

$\mathrm{a}=\operatorname{polyfit}(\mathrm{x}, \mathrm{y}, 1)$

$\mathrm{b}=\operatorname{polyfit}(\mathrm{x}, \mathrm{y} 1,1)$

$\mathrm{c}=\operatorname{polyfit}(\mathrm{x}, \mathrm{y} 2,1)$

$\operatorname{plot}\left(\mathrm{x}, \operatorname{polyval}(\mathrm{a}, \mathrm{x}), \mathrm{\prime}^{\mathrm{k}-}\right)$;

plot(x1,polyval(b,x1),'r-');

plot(x2,polyval(c,x2),'g-');

set(gca,'xlim',[0;40])

grid off 


\section{APPENDIX D}

\section{MATLAB code used to generate plots for mean stress vs. amplitude stress}

Example of MATLAB code used to generate plots and exponential fit line for ratcheting mean stress/yield stress vs. stress amplitude/yield stress

clear all;

clc;

format long

$\mathrm{x}=[1.2 ; 1 ; 0.8]$

$\mathrm{y}=[0.2 ; 0.4 ; 0.6]$;

hold on

$\mathrm{f}=$ fit $\left(\mathrm{x}, \mathrm{y}, \mathrm{exp}^{\prime}\right)$

$\operatorname{plot}(\mathrm{f}, \mathrm{x}, \mathrm{y})$

ylabel('Mean Stess/Yeild Stress')

xlabel('Amplitude Stress/Yield Stress')

grid off 


\section{APPENDIX E}

MATLAB code used to generate three dimensional surface

Example of MATLAB code used to generate three dimensional surface where mean stress as $\mathrm{x}$ axis, stress amplitude as y axis and ratcheting strain rate as $\mathrm{z}$ axis

clear all;

clc;

$\mathrm{x}=[10 ; 20 ; 30 ; 10 ; 10 ; 10 ; 8.25 ; 10]$;

$\mathrm{y}=[130 ; 130 ; 130 ; 130 ; 140 ; 150 ; 130 ; 126.28]$;

$[\mathrm{x}, \mathrm{y}]=$ meshgrid $(8.25: 30,126.28: 150)$

$\mathrm{z}=(0.0005465 * \mathrm{x})+(0.000673 * \mathrm{y})-0.0895633$;

figure

$\operatorname{mesh}(\mathrm{x}, \mathrm{y}, \mathrm{z})$

set(gca,'xlim',[0;70])

set(gca,'ylim',[110;190])

hold on 